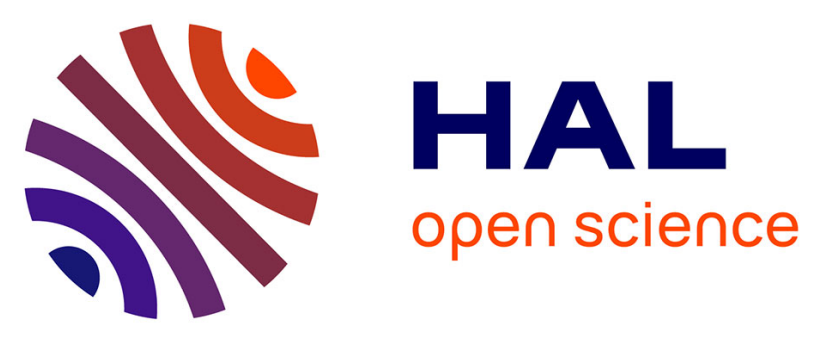

\title{
Use of automated fetal heart rate analysis to identify risk factors for umbilical cord acidosis at birth
}

A. Houzé de L'aulnoit, M. Génin, S. Boudet, R. Demailly, C. Ternynck, G. Babykina, D. Houzé de L'aulnoit, R. Beuscart

\section{- To cite this version:}

A. Houzé de L'aulnoit, M. Génin, S. Boudet, R. Demailly, C. Ternynck, et al.. Use of automated fetal heart rate analysis to identify risk factors for umbilical cord acidosis at birth. Computers in Biology and Medicine, 2019, 115, pp.103525 -. 10.1016/j.compbiomed.2019.103525 . hal-03488410

\author{
HAL Id: hal-03488410 \\ https://hal.science/hal-03488410
}

Submitted on 21 Dec 2021

HAL is a multi-disciplinary open access archive for the deposit and dissemination of scientific research documents, whether they are published or not. The documents may come from teaching and research institutions in France or abroad, or from public or private research centers.
L'archive ouverte pluridisciplinaire HAL, est destinée au dépôt et à la diffusion de documents scientifiques de niveau recherche, publiés ou non, émanant des établissements d'enseignement et de recherche français ou étrangers, des laboratoires publics ou privés.

\section{다)(1) $(5$}

Distributed under a Creative Commons Attribution - NonCommerciall 4.0 International 


\section{Title page}

Use of automated fetal heart rate analysis to identify risk factors for umbilical cord acidosis at birth.

Short title: Clinical and automated FHR risk factors for fetal acidosis

A. Houzé de l'Aulnoit ${ }^{1,2}$, M. Génin ${ }^{1}$, S. Boudet ${ }^{3}$, R. Demailly², C. Ternynck ${ }^{1}$, G. Babykina ${ }^{1}$, D. Houzé de l'Aulnoit ${ }^{2}$, R. Beuscart ${ }^{1}$

${ }^{1}$ Univ. Lille, EA 2694 - Santé publique: épidémiologie et qualité des soins, F-59000 Lille, France

2 Department of Obstetrics, Lille Catholic Hospital, Lille Catholic University, F-59020 Lille, France

${ }^{3}$ Biomedical Signal Processing Unit (UTSB), Lille Catholic University, F-59800 Lille, France

\section{Corresponding author}

Dr Agathe Houzé de l'Aulnoit Department of Obstetrics, Saint Vincent de Paul Hospital, Boulevard de Belfort, BP 387, F-59020 Lille cedex, France

$+33-320-874-836$

ahouzedelaulnoit@yahoo.fr

houze-de-1-aulnoit.agathe@ghicl.net

The authors did not report any potential conflicts of interest. 


\section{Précis}

In addition to clinical predictors, an automated fetal heart rate analysis highlighted other parameters that were significantly associated with fetal acidosis during labor. 
Keywords: cord blood gas analysis; neonatal acidosis; cardiotocography; fetal monitoring; neonatal outcome; neonatal acidaemia; intrapartum risk factors; computer-assisted; fetal hypoxia

\section{Abstract \\ Objective}

To identify clinical parameters and intrapartum fetal heart rate parameters associated with a risk of umbilical cord acidosis at birth, using an automated analysis method based on empirical mode decomposition (Lu and Wei 2012).

\section{Methods}

Our single-center study included 381 cases (arterial cord blood $\mathrm{pH}$ at birth $\mathrm{pHa} \leq 7.15$ ) and 1860 controls $(\mathrm{pHa} \geq 7.25$ ) extracted from a database comprising 8,383 full datasets for over-18 mothers after vaginal or caesarean non-twin, non-breech deliveries at term (> 37 weeks of amenorrhea). The analysis of a 120-minute period of the FHR recording (before maternal pushing or the decision to perform a caesarean section during labor) led to the extraction of morphological, frequency-related, and long- and short-term heart rate variability variables. After univariate analyses, sparse partial least square selection and logistic regression were applied.

\section{Results}

Several clinical factors were predictive of fetal acidosis in a multivariate analysis: nulliparity (odds ratio (OR) 95\% confidence interval (CI)]: 1.769 [1.362 - 2.300]), a male fetus (1.408 [1.097 $-1.811])$, and the term of the pregnancy $(1.333[1.189-1.497])$. The risk of acidosis increased with the time interval between the end of the FHR recording and the delivery $(\mathrm{OR}[95 \% \mathrm{CI}]$ for a 1-minute increment: $1.022[1.012-1.031])$. The risk factors related to the FHR signal were mainly the difference between the mean baseline and the mean FHR (OR [95\%CI]: 1.292 [1.174 $1.424])$, the baseline range $(1.027$ [1.014 - 1.040]), fetal bradycardia $(1.038[1.003-1.075])$ and the late deceleration area $(1.002[1.000-1.005])$. The area under the curve for the multivariate model was $0.79[0.76 ; 0.81]$. 


\section{Conclusion}

In addition to clinical predictors, the automated FHR analysis highlighted other significant predictors, such as the baseline range, the instability of the FHR signal and the late deceleration area. This study further extends the routine application of automated FHR analysis during labor and, ultimately, contributes to the development of predictive scores for fetal acidosis. 
Manuscript (4871 words)

\section{INTRODUCTION}

The fetal heart rate (FHR) is correlated with the fetal brain's oxygenation status. When the FHR is abnormal, the fetus is at risk of hypoxia; this translates into respiratory acidosis, metabolic acidosis (as a means of adapting to the decrease in oxygen levels) and, ultimately, complications in all the fetus's organ systems (the brain, the respiratory system, etc.) ${ }^{1}$.

In routine practice, the heart rate is analyzed visually with regard to several basic parameters: the baseline (the mean FHR observed during stable periods), the variability (the variation in amplitude during stable periods), accelerations (transient increases in the FHR), decelerations (transient decreases in FHR), and the sinusoidal pattern ${ }^{2}$. The interpretation of FHR recordings is subject to significant inter-observer and intra-observer variability ${ }^{3-5}$. So, several groups have therefore developed automated methods for FHR analysis, with a view to eliminating intra- and inter-expert variability and better predicting the risk of acidosis ${ }^{6-10}$. When compared with a human expert, these automated analysis methods (AAMs) yield a more precise calculation of certain basic FHR parameters, and also measure or calculate parameters that cannot be estimated by eye (such as long-term and short-term heart rate variability (LTV and STV, respectively) ${ }^{11}$ ) and are affected by metabolic acidosis during labor ${ }^{12,13}$.

In previous work ${ }^{14,15}$, our group compared eleven AAMs after they had been reprogrammed by using the information specified in the original publications. We compared the baselines and the morphological parameters of the FHR recording (accelerations/decelerations (A/D)) generated by the 11 AAMs with a four-expert consensus. Both studies confirmed the superiority of Lu and Wei's AAM (hereafter referred to as the LW AAM) ${ }^{16}$, which agreed most closely with a "gold standard" expert consensus.

The ultimate goal of an AAM is to improve screening for fetal acidosis during labor and thus facilitate the obstetrician's decision-making process. Hence, the primary objective of the present 
study was to identify predictive factors (clinical parameters and/or those generated by the LW AAM during labor) for fetal acidosis.

\section{MATERIALS AND METHODS}

\subsection{Study population}

This was a single-center study of women having given birth at Saint Vincent de Paul Maternity Hospital (Lille, France) between February $1^{\text {st }}, 2011$, and December $31^{\text {st }}, 2016$.

The study's objectives and procedures were approved by the local independent ethics committee (CIER GHICL, Lille, France) on August 4 2016 (reference: 2016-06-08). A data warehouse containing 10,837 delivery files (Figure 1) was registered with the French National Data Protection Commission (Commission nationale de l'informatique et des libertés, Paris, France; reference: REG-077) on September $3^{\text {rd }}, 2017$. The "Bien Naître" study database $(8,383$ full datasets with the mothers' clinical data, data on the delivery and the newborn's status at birth, and digitized recordings of the FHR signal during labor) was extracted from the data warehouse.

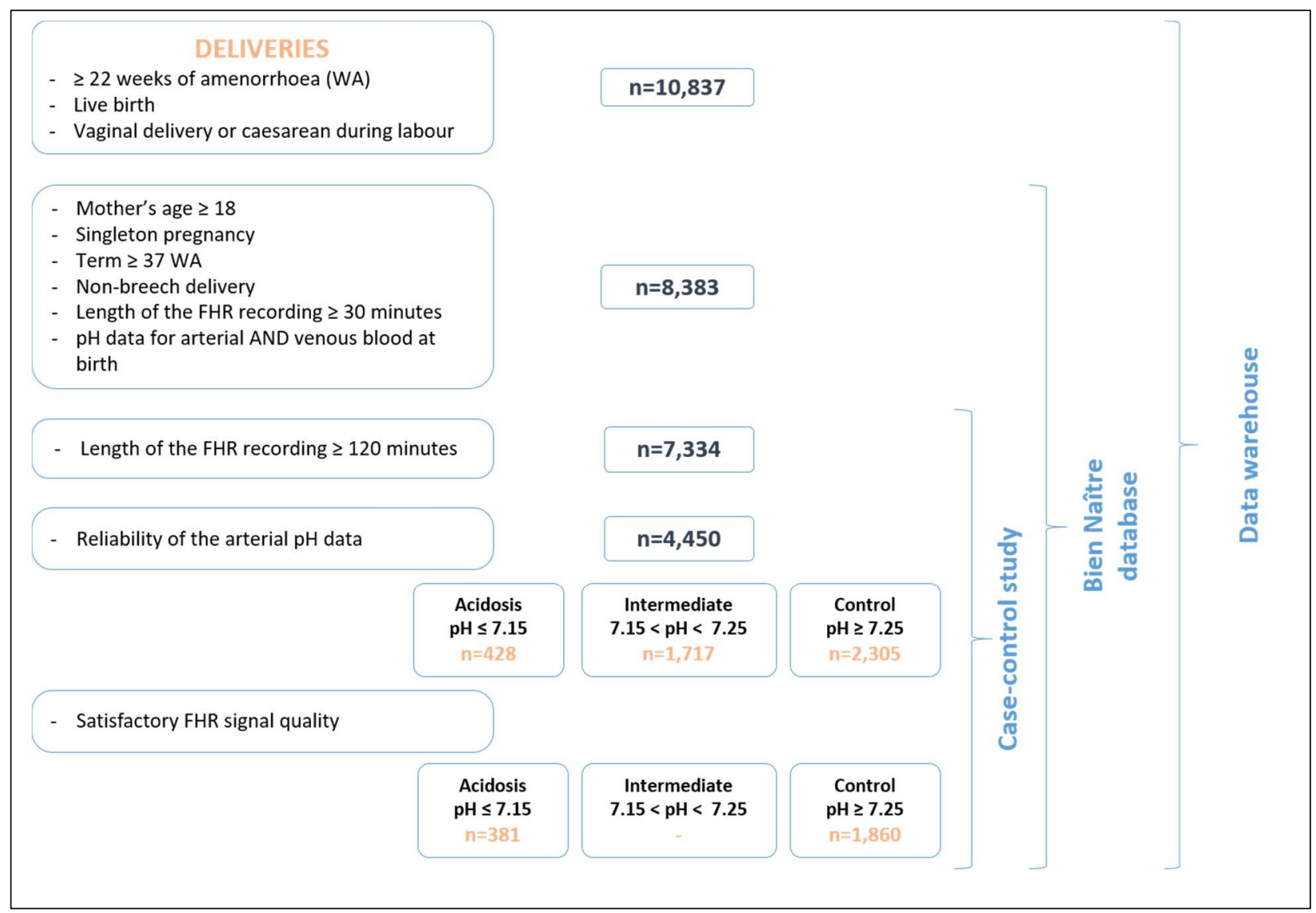


Figure 1. Study flowchart

Women for whom essential data were missing (i.e. the absence of cord blood gas data at birth, the absence of an FHR recording (due to fetal death, caesarean deliveries prior to labor), or an FHR recording of less than 30 minutes (failure to record the FHR during labor, or rapid delivery) were excluded from the study database. Deliveries by mothers under the age of 18 , women with multiple pregnancies, breech presentations, and premature deliveries were also excluded from the study database.

The study database included anonymized data on adult (over 18) mothers after vaginal or caesarean non-twin, non-breech deliveries at term ( $>37$ weeks of amenorrhea (WA)).

\subsection{Acquisition of clinical and biochemical data}

The clinical data on the mothers included the obstetrical history (gravidity, parity, prior low transverse caesarean, etc.), gestational pathologies (diabetes, vascular conditions, etc.) and the body mass index. The characteristics of the labor (induction, duration of the labor, and the colour of the amniotic fluid) and the mode of delivery (non-operative vaginal delivery, operative delivery or caesarean section) were also documented. In routine practice in our maternity hospital, the FHR is recorded continuously until birth (for vaginal deliveries) or until a decision to perform a cesarean is taken. Birth has to take place within 15 minutes of the decision to perform a cesarean when the FHR recording is "pathologic" (according to the FIGO classification), within 30 minutes for a "suspect" FHR, and within 60 minutes for a FHR that is not suggestive of a risk of acidosis. The FHR is not monitored during the transfer to the cesarean operating room.

The clinical data on the newborns included the sex, birth weight, and term. Macrosomia was defined as a birth weight greater than the $90^{\text {th }}$ percentile for the term, and intra-uterine growth restriction was defined as a birth weight below the $3^{\text {rd }}$ percentile for the term, according to the curves shown in reference ${ }^{17}$. The newborn's status at birth was assessed by calculating the Apgar 
score ${ }^{18}$. Transfers to the intensive care unit or early perinatal deaths (i.e. death within 7 days of delivery) were noted.

In the present case-control study, we selected women whose cord blood gas measurements were satisfactory and physiologically valid (defined as an arterial blood $\mathrm{pH}$ value at least 0.02 units below the venous $\mathrm{pH}$ value and an arterial $\mathrm{pCO}_{2}$ at least $3.75 \mathrm{mmHg}$ greater than the venous $\mathrm{pCO}_{2}$ $\left.{ }^{19,20}\right)$. Immediately after delivery, a segment of the umbilical cord was clamped. Arterial and venous blood samples were collected and analyzed for $\mathrm{pH}$ and blood gases using a bedside system (ABL90 FLEX, Radiometer, Copenhagen, Denmark).

\subsection{Acquisition of FHR data}

\subsubsection{Preprocessing}

The FHR signal was recorded by using either a Doppler ultrasound probe placed on the mother's abdomen or an electrode placed on the fetus's scalp. The FHR was calculated using an autocorrelation technique and a fetal monitor (AVALON FM50, Philips Healthcare, Amsterdam, The Netherlands). Signals were recorded digitally at a sampling frequency of $4 \mathrm{~Hz}$.

The study's FHR database included 4450 files with at least 2 hours of FHR recording and a valid criterion for evaluation (pHa). An obstetrician with expertise in FHR analysis reviewed the 120minute period before maternal pushing or before the decision to perform a caesarean section, and checked the signal quality (i.e. deletion of missing data periods lasting more than 2 min, and deletion of periods with interference from the mother's heart rate), so that the LW AAM would be able to perform as well as possible (Figure 1).

To remove aberrant samples, all the FHR recordings were pre-processed using the algorithm described in ${ }^{8}$. The LW AAM ${ }^{16}$ programmed in MATLAB identifies the baseline by first performing an empirical mode decomposition to low-pass-filter the FHR. Next, the periods presenting significant differences between two adjacent maximum and minimum values are excluded from the baseline calculation, as are periods far from the average signal. The final 
baseline is determined by cubic spline interpolation. Next, A/D are determined with a standard thresholding method used by several researchers ${ }^{8}$, in compliance with the current International Federation of Gynaecology and Obstetrics (FIGO) guidelines ${ }^{2}$.

\subsubsection{FHR signal data}

The data dictionary is described in the Supplementary Materials (S1). In our morphological analysis, we assessed the basic characteristics of the FHR (the baseline and A/D) with regard to the FIGO guidelines ${ }^{2,21}$. The baseline was defined as the mean FHR level when the recording is stable, free of $\mathrm{A} / \mathrm{D}$, and not affected by contractions of the uterus. An acceleration (A) was defined as a transient increase (by more than $15 \mathrm{bpm}$ ) in the FHR for more than $15 \mathrm{~s}$, whereas as a deceleration (D) was defined as a transient decrease (by more than $15 \mathrm{bpm}$ ) in the FHR for more than $15 \mathrm{~s}$. Furthermore, the different types of deceleration defined in the guidelines (early, late, variable and prolonged) were assessed in terms of the number of episodes and their area relative to the baseline; this provides an estimation of the number of fetal heart beats that would have occurred if the deceleration had not happened ${ }^{22}$. The presence of repetitive decelerations ${ }^{23}$ was also noted.

Several parameters were calculated in order to assess fetal tachycardia and bradycardia. In order to identify automatically periods with an unassignable baseline ${ }^{10}$ - the baseline cannot be reliably defined (whether visually by the clinician or automatically by a computer - and thus to characterize the stability of the FHR, the signal stability index (SSI) and the minimum expected value $(\mathrm{MEV})$ were measured ${ }^{10}$. Presence of an unassignable baseline in the null zone (defined as $\mathrm{SSI}<0.022$ and $\mathrm{MEV}<70 \mathrm{bpm}$ ) and in the intermediate zone (defined as SSI $<0.048$ and $\mathrm{MEV}<$ $86 \mathrm{bpm})$ were noted ${ }^{10}$.

We measured the long-term variability LTV, corresponding to the visible variability in the FHR recording (the amplitude of the oscillations) over a minute (apart from A/D), as defined by the FIGO $^{21}$ and calculated in several studies ${ }^{24,25}$. We also measured the proportion of the recording 
time during which the LTV was abnormal, below $6 \mathrm{bpm}^{8}-$ a situation referred to as silent oscillation (OSC.Sil) by Jezewski et al. ${ }^{26}$. The area for low LTV (the area between the LTV signal and a 6 bpm straight line, when LTV signal is under this line) was also computed; it represents both the duration and the severity of low LTV. We also measured the proportion of the recording time for which the LTV was above $25 \mathrm{bpm}$ (marked LTV) (referred to as saltatory oscillations (OSC.Salt) by Jezewski ${ }^{26}$ ) and the LTV irregularity index (LTI, as defined by De Haan ${ }^{11}$ and adopted by Jezewski et al. ${ }^{26,27}$ ).

Short-term variability STV corresponds to variations in the mean heart rate with regard to consecutive R-R intervals, and reflects appropriate neurological adaptation of the FHR ${ }^{28}$.

The frequency variability was documented in the four bands described by Signorini et al. ${ }^{29}$ : very low frequencies (the VLF band; 0.01-0.03 Hz), low frequencies (the LF band: 0.03-0.15 Hz), middle frequencies (the MF band; 0.15-0.50 Hz) and high frequencies (the HF band; 0.50-1.00 $\mathrm{Hz})$. We also assessed the $\mathrm{LF} /(\mathrm{MF}+\mathrm{HF})$ ratio, which quantifies the status of the autonomic nervous system ${ }^{30}$. The VLF band reflects thermoregulatory processes ${ }^{31}$, the LF and HF bands are linked to the activity of the autonomic nervous system ${ }^{32,33}$, and the MF band is related to fetal movements and the mother's breathing ${ }^{34-36}$. The high frequency variability index (HFVI, described by Logier et al. ${ }^{37}$ ) was reprogrammed.

\subsection{Statistical analysis}

In order to identify predictive factors for fetal acidosis, we decided to perform a case-control study. The type of delivery and the neonatal parameters were not included in the multivariate model because our study was designed to evaluate factors that were accessible prior to delivery, i.e. those generated by an AAM on the basis of the FHR signal during labor. A case was defined as a mother whose child presented with an arterial $\mathrm{pH}$ at birth $\leq 7.15$. A control was defined as a mother whose child did not present with acidosis at birth ( $\mathrm{pHa} \geq 7.25)$. In each group, the quality of the FHR recording was checked. 


\subsubsection{Descriptive analyses}

Quantitative variables were described as the mean \pm standard deviation or the median [interquartile range], depending on whether or not the data were distributed normally (as assessed using a histogram, the Henry line test, and the Shapiro-Wilk test). Qualitative variables were described as the number (percentage).

\subsubsection{Univariate analyses}

The association between the criterion for evaluation (cases of acidosis/controls without acidosis) and the explanatory variables was probed using standard statistical tests. Depending on the data distribution, intergroup differences in quantitative variables were probed by applying-Student's test er the Mann-Whitney-Wilcoxon test. A Fisher's exact test or Pearson's chi-squared test was applied to qualitative variables.

\subsubsection{Multivariate analysis}

Logistic regression models were used to determine predictive factors for acidosis. The variables that were significant in the univariate analyses were fed into a multivariate analysis. Given the large number of strongly intercorrelated variables in the FHR analysis, a sparse partial least squares (SPLS) logistic regression was used to select the variables ${ }^{38-40}$ after cross validation with the matrix relating the number of components to the number of possible variables (based on the mean squared prediction error). All the variables selected by SPLS regression were fed into a classic logistic regression model with stepwise selection, based on maximization of the Akaike information criterion. The model's statistical significance was evaluated in a likelihood ratio test and in Wald's test. The results were quoted as the OR [95\% confidence interval (CI)], and the model's discriminant power was evaluated by calculating the area under the curve (AUC).

In order to provide the person reading the analysis with a clear indication of how the risk of the outcome changes with the variable in question, fold-changes may be most meaningful and most easily understood. A $1 \mathrm{bpm}$ increase in an FHR-related variate may be too small to be considered as relevant. For greater clinical relevance, the effects of continuous FHR-related variables 
(assuming that the variable's logit is linear) were also expressed as the OR for an increment ${ }^{41}$ (chosen as the difference between the variable's $90^{\text {th }}$ percentile and $10^{\text {th }}$ percentile).

$O R=\exp (\delta x \beta)$, where $\delta$ is the increase, and $\beta$ is the variable's logistic regression coefficient.

All the statistical analyses were performed using R software version 3.4.1 (Vienna, Austria) and its pls and sgPLS packages. The threshold for statistical significance was set to $\mathrm{p}<0.05$.

\section{RESULTS}

Among the 2733 complete datasets (out of 4450) that met our inclusion criteria (428 cases with a $\mathrm{pH} \leq 7.15$ and 2305 controls with a $\mathrm{pH} \geq 7.25$ ), the signal quality was judged by the expert to be sufficient for further analysis in 2241 instances (81.9\%): 381 cases (exclusion rate: 10.9\%) and 1860 controls (exclusion rate: 19.3\%). The prevalence of acidosis $(\mathrm{pHa} \leq 7.15)$ in our sample was therefore $17 \%$ (Figure 1).

\subsection{Univariate analyses}

With regard to clinical variables (Table 1), nulliparous women were significantly more frequent in the acidosis group than in the control group (59.3\% vs. $37.4 \%$, respectively; $p<0.001)$. Acidosis was also more frequently observed for operative deliveries $(28.4 \%$, vs. $9.3 \%$ for spontaneous deliveries; $\mathrm{p}<0.001)$ and caesarean sections during labor $(10.7 \%$, vs. $9.3 \%$ for spontaneous deliveries; $\mathrm{p}<0.001$ ). The median duration of labor was longer for cases than for controls (387 min [283.0;490.0] vs. $320 \min [238.0 ; 444.0]$, respectively; $\mathrm{p}<0.001)$, as was the median time interval between the end of the recording and birth for non-operated vaginal deliveries. For cesarean deliveries and operated vaginal deliveries, the median time intervals between the end of the recording and birth were shorter among cases than among controls.

In contrast, we did not observe a relationship between maternal pathologies (prior low transverse caesarean, type 2 diabetes or gestational diabetes, arterial hypertension or preeclampsia) and the occurrence of acidosis. 
Table 1. Clinical variables among cases (acidosis) and controls (no acidosis)

\begin{tabular}{|c|c|c|c|}
\hline Variable & $\begin{array}{c}\text { Cases (acidosis) } \\
\mathrm{n}=381\end{array}$ & $\begin{array}{c}\text { Controls (no acidosis) } \\
n=1860\end{array}$ & $P^{t, \neq, \S}$ \\
\hline Mother's age (years) & $29.0[26.0 ; 33.0]$ & $29.0[26.0 ; 33.0]$ & $0.954^{+}$ \\
\hline $\begin{array}{l}\text { Body mass index at the end of } \\
\text { pregnancy }\left(\mathrm{kg} / \mathrm{m}^{2}\right)\end{array}$ & $28.3[25.9 ; 31.6]$ & $27.9[25.7 ; 31.2]$ & $0.286^{+}$ \\
\hline Parity & $1.0[1.0 ; 2.0]$ & $2.0[1.0 ; 3.0]$ & $<0.001^{+}$ \\
\hline Nulliparity & $226(59.3)$ & $696(37.4)$ & $<0.001^{\ddagger}$ \\
\hline Term (weeks of amenorrhea) & $40.2[39.4 ; 41.0]$ & $39.7[39.0 ; 40.5]$ & $<0.001^{+}$ \\
\hline Prior low transverse caesarean & $36(9.4)$ & $123(6.6)$ & $0.064^{\ddagger}$ \\
\hline $\begin{array}{l}\text { Gestational diabetes and/or type II } \\
\text { diabetes }\end{array}$ & $43(11.3)$ & $234(12.6)$ & $0.539^{\ddagger}$ \\
\hline $\begin{array}{l}\text { Arterial hypertension and/or } \\
\text { preeclampsia }\end{array}$ & $6(1.6)$ & $19(1.0)$ & $0.417^{\ddagger}$ \\
\hline Induction & $94(24.7)$ & $522(28.1)$ & $0.198^{\ddagger}$ \\
\hline Locoregional anesthesia & $370(97.1)$ & 1783 (95.9) & $0.316^{\ddagger}$ \\
\hline Meconium in the amniotic fluid & $47(12.3)$ & $93(5.0)$ & $<0.001^{\ddagger}$ \\
\hline Total time in labor (minutes) & $387.0[283.0 ; 490.0]$ & $320.0[238.0 ; 444.0]$ & $<0.001^{+}$ \\
\hline $\begin{array}{l}\text { Time interval between the end of } \\
\text { the FHR recording and birth } \\
\text { (minutes) } \\
\text { all type of deliveries } \\
\text { vaginal, non-operative } \\
\text { vaginal, operative } \\
\text { caesarean, during labor }\end{array}$ & $\begin{array}{l}23.0[16.0 ; 35.0] \\
21.0[14.0 ; 32.0] \\
31.0[19.8 ; 42.0] \\
16.0[14.0 ; 21.0]\end{array}$ & $\begin{array}{l}19.0[11.0 ; 29.0] \\
17.0[10.0 ; 26.0] \\
39.0[30.0 ; 48.0] \\
24.0[19.0 ; 29.0]\end{array}$ & $<0.001^{+}$ \\
\hline $\begin{array}{l}\text { Type of delivery: } \\
\text { vaginal, non-operative } \\
\text { vaginal, operative } \\
\text { caesarean, during labor }\end{array}$ & $\begin{array}{c}232(60.9) \\
108(28.4) \\
41(10.7) \\
\end{array}$ & $\begin{array}{c}1514(81.4) \\
173(9.3) \\
173(9.3) \\
\end{array}$ & $<0.001^{\ddagger}$ \\
\hline Birth weight (g) & $3435.0[3160.0 ; 3725.0]$ & $3380.0[3088.7 ; 3695.0]$ & $0.096^{+}$ \\
\hline A 5-minute Apgar score below 7 & $16(4.2)$ & $6(0.3)$ & $<0.001^{\ddagger}$ \\
\hline Transfer to the intensive care unit & $22(5.8)$ & $18(0.9)$ & $<0.001^{\ddagger}$ \\
\hline $\begin{array}{l}\text { Newborn's sex } \\
\text { female } \\
\text { male }\end{array}$ & $\begin{array}{l}165(43.3) \\
216(56.7)\end{array}$ & $\begin{array}{l}920(49.5) \\
940(50.5)\end{array}$ & $0.033^{\ddagger}$ \\
\hline Macrosomia & $55(14.4)$ & $272(14.6)$ & $0.988^{\ddagger}$ \\
\hline Intrauterine growth restriction & $4(1.0)$ & $15(0.8)$ & $0.549^{\S}$ \\
\hline
\end{tabular}

Concerning FHR variables (Tables 2 and 3), the median SSI and MEV values were significantly lower in cases than controls $(7.2[5.7 ; 8.8]$ vs. $8.2[6.8 ; 9.8]$, respectively, for the SSI $p<0.001 ; 97.9$ 
[85.4;108.8] vs. 102.6 [92.9;111.5], respectively; for the MEV; $\mathrm{p}<0.001)$. The presence of a nonassignable baseline in the null zone was more frequent in cases than in controls $(28.3 \%$ vs. $8.9 \%$, respectively; $\mathrm{p}<0.001)$ as was the presence of a non-assignable baseline in the intermediate zone ( $75.1 \%$ vs. $51.0 \%$, respectively; $\mathrm{p}<0.001)$; these differences attested to a greater likelihood of signal instability in cases of acidosis. Although signal loss was uncommon, it was more frequent in cases than in controls $(5.6 \%[3.1 ; 9.8]$ vs. $4.8 \%[2.18 ; 8.5]$, respectively).

Table 2. Comparison of the morphological FHR variables among cases and controls.

\begin{tabular}{|c|c|c|c|}
\hline Variable & $\begin{array}{c}\text { Cases (acidosis) } \\
\mathrm{n}=381\end{array}$ & $\begin{array}{l}\text { Controls (no acidosis) } \\
n=1860\end{array}$ & $\mathrm{p}^{t, \neq}$ \\
\hline Signal loss (\%) & $5.6[3.10 ; 9.80]$ & $4.80[2.18 ; 8.50]$ & $<0.001^{+}$ \\
\hline Signal stability index $x 100$ & $7.20[5.70 ; 8.80]$ & $8.20[6.80 ; 9.80]$ & $<0.001^{+}$ \\
\hline Minimum expected value MEV (bpm) & $97.95[85.39 ; 108.79]$ & $102.64[92.92 ; 111.46]$ & $<0.001^{+}$ \\
\hline $\begin{array}{l}\text { Presence of an unassignable baseline in the } \\
\text { null zone }\end{array}$ & $108(28.3)$ & $165(8.9)$ & $<0.001^{\neq}$ \\
\hline $\begin{array}{l}\text { Presence of an unassignable baseline in the } \\
\text { intermediate zone }\end{array}$ & $286(75.1)$ & $948(51.0)$ & $<0.001^{\neq}$ \\
\hline FHR range (bpm) & $31.00[25.25 ; 38.75]$ & $27.00[22.25 ; 33.00]$ & $<0.001^{+}$ \\
\hline Standard deviation of the FHR (bpm) & $4.76[3.81 ; 5.84]$ & $4.34[3.62 ; 5.16]$ & $<0.001^{+}$ \\
\hline Mean baseline - mean FHR (bpm) & $1.64[0.21 ; 3.12]$ & $0.39[-0.42 ; 1.39]$ & $<0.001^{+}$ \\
\hline \multicolumn{4}{|l|}{ Time during which the baseline was * } \\
\hline _ below 110 bpm (\%) & $0.00[0.00 ; 58.30]$ & $0.00[0.00 ; 47.68]$ & $<0.001^{+}$ \\
\hline - above 160 bpm (\%) & $0.00[0.00 ; 100.00]$ & $0.00[0.00 ; 100.00]$ & $<0.001^{+}$ \\
\hline \multicolumn{4}{|l|}{ Baseline area (beats) * } \\
\hline - below $110 \mathrm{bpm}$ & $0.00[0.00 ; 5.53]$ & $0.00[0.00 ; 5.02]$ & $<0.001^{+}$ \\
\hline - above $160 \mathrm{bpm}$ & $0.00[0.00 ; 20.94]$ & $0.00[0.00 ; 24.77]$ & $<0.001^{+}$ \\
\hline Baseline range (bpm) & $31.89[22.11 ; 42.77]$ & $22.60[17.23 ; 30.13]$ & $<0.001^{+}$ \\
\hline Total number of accelerations & $15.00[8.00 ; 23.00]$ & $15.00[9.00 ; 24.00]$ & $0.129^{+}$ \\
\hline Total acceleration area (beats) & $112.10[57.80 ; 181.80]$ & $111.40[58.40 ; 185.40]$ & $0.832^{+}$ \\
\hline Total number of decelerations & $24.00[15.00 ; 33.00]$ & $18.00[11.00 ; 26.00]$ & $<0.001^{+}$ \\
\hline \multicolumn{4}{|l|}{ Numbers of: } \\
\hline prolonged decelerations (>120 s) & $1.00[0.00 ; 2.00]$ & $0.00[0.00 ; 1.00]$ & $<0.001^{+}$ \\
\hline early decelerations & $1.00[0.00 ; 3.00]$ & $1.00[0.00 ; 2.00]$ & $<0.001^{+}$ \\
\hline late decelerations & $2.00[1.00 ; 4.00]$ & $1.00[0.00 ; 2.00]$ & $<0.001^{+}$ \\
\hline variable decelerations & $18.00[11.00 ; 25.00]$ & $14.50[9.00 ; 22.00]$ & $<0.001^{+}$ \\
\hline Total deceleration area (beats) & $333.15[166.21 ; 555.88]$ & $171.36[86.71 ; 295.13]$ & $<0.001^{+}$ \\
\hline
\end{tabular}




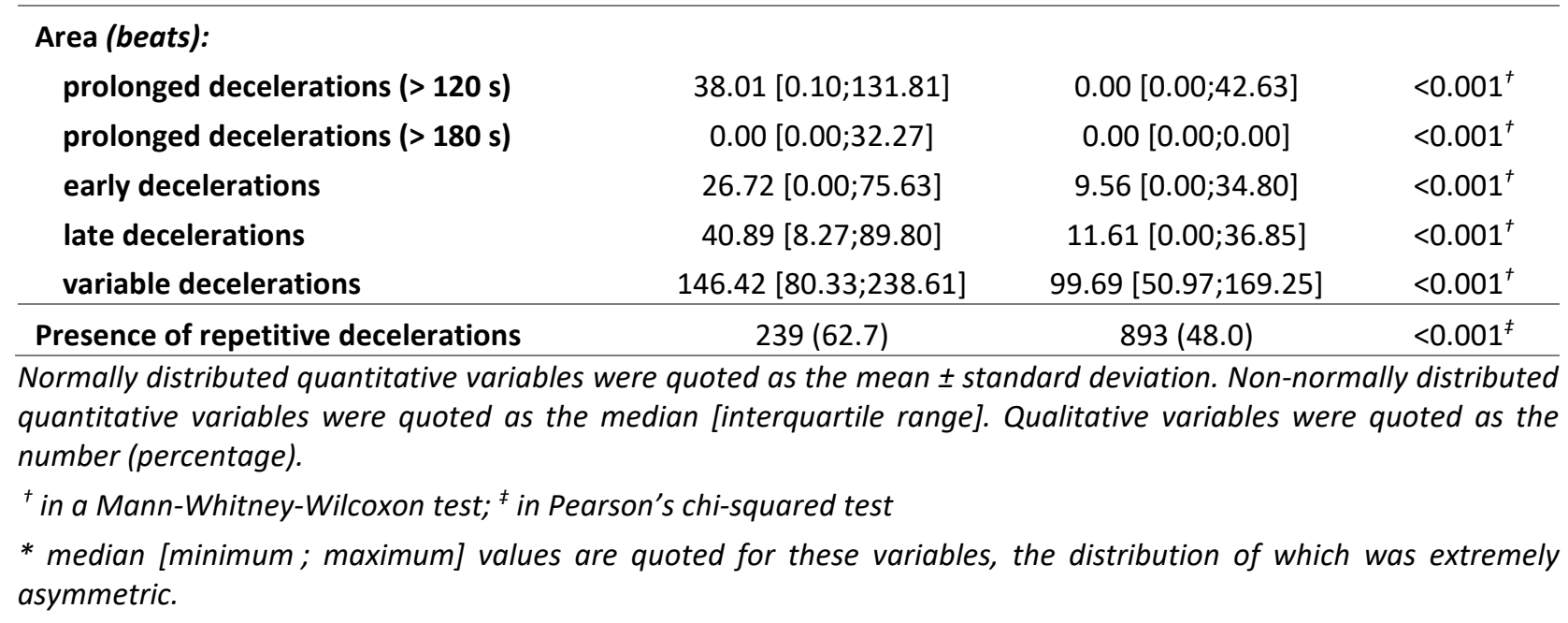

Table 3. The FHR variability variables in the case and control groups

\begin{tabular}{|c|c|c|c|}
\hline Variable & $\begin{array}{c}\text { Cases (acidosis) } \\
\mathrm{n}=381 \\
\end{array}$ & $\begin{array}{c}\text { Controls (no acidosis) } \\
n=1860\end{array}$ & $p^{+}$ \\
\hline \multicolumn{4}{|l|}{ Long-term variability (LTV) } \\
\hline LTV (bpm) & $14.80[13.07 ; 17.15]$ & $14.59[12.90 ; 16.63]$ & 0.131 \\
\hline Low LTV < 6 bpm (\%) & $3.83[0.92 ; 8.36]$ & $3.15[0.99 ; 7.75]$ & 0.337 \\
\hline Marked LTV > 25 bpm (\%) & $6.81[3.88 ; 12.98]$ & $6.30[3.29 ; 10.99]$ & 0.012 \\
\hline Area under the LTV curve $<6 \mathrm{bpm}(\mathrm{bpm})$ & $0.05[0.01 ; 0.10]$ & $0.04[0.01 ; 0.09]$ & 0.345 \\
\hline LTI (msec) & $24.32[20.52 ; 29.93]$ & $22.98[19.24 ; 27.37]$ & $<0.001$ \\
\hline \multicolumn{4}{|l|}{ Short-term variability (STV) } \\
\hline SD STV (bpm) & $4.76[3.81 ; 5.84]$ & $4.34[3.62 ; 5.16]$ & $<0.001$ \\
\hline STV < 1 bpm (\%) & $74.67[68.15 ; 79.99]$ & $76.37[70.35 ; 81.51]$ & 0.001 \\
\hline STV (bpm) & $2.69[2.20 ; 3.21]$ & $2.58[2.13 ; 3.11]$ & $<0.05$ \\
\hline STV II (bpm) x 100 & $20.00[16.38 ; 24.67]$ & $25.40[20.63 ; 30.23]$ & $<0.001$ \\
\hline STI (radians) x 100 & $1.09[0.85 ; 1.38]$ & $1.12[0.89 ; 1.40]$ & 0.233 \\
\hline \multicolumn{4}{|l|}{ Frequency variables } \\
\hline$P_{V L F}\left(b p m^{2}\right) \times 100$ & $13.85[7.79 ; 20.54]$ & $10.74[6.92 ; 16.08]$ & $<0.001$ \\
\hline$P_{L F}\left(b p m^{2}\right) \times 100$ & $9.11[6.04 ; 12.79]$ & $8.15[5.61 ; 11.33]$ & $<0.001$ \\
\hline$P_{M F}\left(b p m^{2}\right) \times 100$ & $1.09[0.76 ; 1.70]$ & $0.96[0.67 ; 1.41]$ & $<0.001$ \\
\hline$P_{\mathrm{HF}}\left(b p m^{2}\right) \times 100$ & $0.13[0.09 ; 0.19]$ & $0.12[0.09 ; 0.17]$ & $<0.001$ \\
\hline $\mathbf{P}_{\mathrm{LF}} /\left(\mathbf{P}_{\mathrm{MF}}+\mathbf{P}_{\mathrm{HF}}\right)$ ratio & $6.97[5.43 ; 8.94]$ & $7.06[5.59 ; 8.86]$ & 0.600 \\
\hline High frequency variability index HFVI & $0.96[0.84 ; 1.04]$ & $1.01[0.91 ; 1.08]$ & $<0.001$ \\
\hline
\end{tabular}

Non-normally distributed quantitative variables were quoted as the median [interquartile range]. For scaling reasons, some results are multiplied by 100.

t in a non-parametric Mann-Whitney-Wilcoxon test

LTI: long-term irregularity; II: interval index; SD: standard deviation; STI: short-term irregularity; P: power; VLF: very low frequency $(0.01-0.03 \mathrm{~Hz})$; LF: low frequency $(0.03-0.15 \mathrm{~Hz}) ; \mathrm{MF}$ : mild frequency $(0.15-0.50 \mathrm{~Hz})$; HF: high frequency $(0.50-1.00 \mathrm{~Hz})$ 
Concerning the baseline, an abnormal baseline (below $110 \mathrm{bpm}$ and above $160 \mathrm{bpm}$ ) was more frequent in cases than in controls $(\mathrm{p}<0.001)$ (Table 2). The median baseline range was greater for cases than for controls $(31.9$ [22.1; 42.8] vs. 22.6 [17.2; 30.1], respectively; $p<0.001)$.

Acidosis was significantly associated with all the variables (frequencies and magnitudes) related to decelerations $(\mathrm{p}<0.001)$. In contrast, we did not observe a significant association between acidosis and the presence of accelerations $(\mathrm{p}=0.129)$.

With regard to LTV (Table 3), the median LTI was greater in the acidosis group than in the control group $(24.32$ [20.52; 29.93] vs. 22.98 [19.24; 27.37], respectively; $p<0.001)$, as was the median marked LTV $(6.81$ [3.88; 12.98$]$ vs. 6.30 [3.29; 10.99], respectively; $p=0.012)$. In contrast, the minimum LTV value did not appear to be significantly associated with the presence of acidosis $(\mathrm{p}=0.337)$. The median STV was greater in the acidosis group than in the control group (2.69 [2.20; 3.21] vs. 2.58 [2.13; 3.11], respectively; $\mathrm{p}<0.001)$. An STV value below 1 bpm was less frequent in the acidosis group than in the control group $(74.67 \%[68.15 ; 79.99]$ vs. $76.37 \%$ [70.35; 81.51], respectively; $\mathrm{p}=0.001$ ) (Table 3). The median STV II value was lower in the acidosis group than in the control group $(20.00$ [16.38; 24.67] vs. 25.40 [20.63; 30.23], p<0.001). The median power values for each of the four frequency bands were significantly greater in the acidosis group than in the control group $(\mathrm{p}<0.001)$. In contrast, the median HFVI was lower in the acidosis group than in the control group $(0.96[0.84 ; 1.04]$ vs. $1.01[0.91 ; 1.08]$, respectively; $\mathrm{p}<0.001)$.

\subsection{Multivariate analysis}

The partial least squares method enabled us to eliminate a significant number of collinear variables, and to select a subset of 22 variables for stepwise logistic regression. Eleven of these variables were found to be significant, and the logistic regression model was significant $(\mathrm{p}<0.0001)$. The model also had a high discriminant ability $(\mathrm{AUC}[95 \% \mathrm{CI}]=0.79[0.76 ; 0.81])$. The influence of each variable (after adjustment) is shown in Table 4. 
Table 4. The logistic regression model, and determinants of the risk of fetal acidosis

\begin{tabular}{|c|c|c|c|c|c|}
\hline Variable & $\begin{array}{l}\text { Unit/difference }\left(90^{\text {th }} \text { - }\right. \\
\left.10^{\text {th }}\right) \text { or reference }\end{array}$ & $\begin{array}{c}\text { Slope } \\
\text { coefficient }\end{array}$ & $\begin{array}{c}\text { OR }[95 \% \mathrm{Cl}] \\
\text { per unit or according } \\
\text { to a reference }\end{array}$ & $\begin{array}{c}\text { OR }[95 \% \mathrm{Cl}] \\
\text { per difference }\left(90^{\text {th }}-10^{\text {th }}\right)\end{array}$ & $\mathrm{p}$ \\
\hline Nulliparity & yes vs. no & 0.570 & $1.769[1.362-2.300]$ & - & $<0.0001$ \\
\hline Term & $1 \mathrm{WA}$ & 0.287 & $1.333[1.189-1.497]$ & - & $<0.0001$ \\
\hline Sex of the newborn & male vs. female & 0.342 & $1.408[1.097-1.811]$ & - & $<0.01$ \\
\hline $\begin{array}{l}\text { Time interval between the end of } \\
\text { recording and the delivery }\end{array}$ & $\begin{array}{c}1 \mathrm{~min} \\
\Delta 30 \min \end{array}$ & 0.021 & $1.022[1.012-1.031]$ & $1.906[1.443-2.515]$ & $<0.0001$ \\
\hline Minimum expected value MEV & $\begin{array}{c}1 \mathrm{bpm} \\
\Delta 40 \mathrm{bpm}\end{array}$ & 0.019 & $1.019[1.007-1.032]$ & $2.169[1.344-3.511]$ & $<0.01$ \\
\hline Mean baseline - mean FHR & $\begin{array}{c}1 \mathrm{bpm} \\
\Delta 4 \mathrm{bpm}\end{array}$ & 0.256 & $1.292[1.174-1.424]$ & $2.786[1.905-4.117]$ & $<0.0001$ \\
\hline $\begin{array}{l}\text { Time during which the baseline } \\
\text { was below } 110 \mathrm{bpm}\end{array}$ & $\begin{array}{c}1 \% \\
\Delta 10 \% \\
\end{array}$ & 0.037 & $1.038[1.003-1.075]$ & $1.445[1.026-2.057]$ & $<0.05$ \\
\hline Baseline range & $\begin{array}{c}1 \mathrm{bpm} \\
\Delta 30 \mathrm{bpm}\end{array}$ & 0.027 & $1.027[1.014-1.040]$ & $2.230[1.539-3.247]$ & $<0.0001$ \\
\hline Total area for late decelerations & $\begin{array}{c}1 \text { beat } \\
\Delta 100 \text { beats }\end{array}$ & 0.002 & $1.002[1.000-1.005]$ & $1.268[1.023-1.582]$ & $<0.05$ \\
\hline LTI & $\begin{array}{c}1 \mathrm{msec} \\
\Delta 15 \mathrm{msec}\end{array}$ & 0.047 & $1.048[1.021-1.075]$ & $2.017[1.369-2.974]$ & $<0.001$ \\
\hline STV II & $\begin{array}{c}1 \mathrm{bpm} \\
\Delta 15 \mathrm{bpm}\end{array}$ & -0.051 & $0.950[0.925-0.975]$ & $0.463[0.313-0.681]$ & $<0.001$ \\
\hline
\end{tabular}

The variables are expressed according to a reference (if qualitative) or per unit and as the difference between the variable's 90 th percentile and 10th percentile (if quantitative).

LTI: long term irregularity; STV II: interval index short term variability

The logistic regression showed that several clinical and FHR-related factors were predictive of fetal acidosis. The clinical risk factors were nulliparity (OR [95\%CI]: 1.769 [1.362 - 2.300]), a male fetus $(1.408$ [1.097 - 1.811]), and late-term pregnancy $(1.333$ [1.189 - 1.497]). The FHRrelated risk factors were a greater difference between the mean baseline and the mean FHR (OR [95\%CI]: $1.292[1.174-1.424])$, the baseline range $(1.027[1.014-1.040])$, the MEV (1.019 [1.007 - 1.032]), fetal bradycardia (the time during which the baseline was below $110 \mathrm{bpm}(1.038$ $[1.003-1.075]))$, the total area for late decelerations $(1.002[1.000-1.005])$. The effect of these variables on the risk of fetal acidosis is clearer when one considers a variation of more than a single unit, as this would be more relevant for clinician. Thus, the estimated OR for a 30-minute increment in the time interval between the end of the recording and the delivery is $\mathrm{OR}(30)=\exp (30$ 
$\mathrm{x} 0.0215)=1.90$. This indicates that for every 30 -minute increment in the time interval between the end of recording and the delivery, the risk of acidosis increases 1.90 -fold. A difference in the MEV of 40 bpm multiplied the risk by 2.169 [1.344 - 3.511]. If the baseline is below 110 bpm for $10 \%$ of the recording time, the risk of acidosis is multiplied by 1.445 [1.026 - 2.057]. The estimated $\mathrm{OR}$ for a $30 \mathrm{bpm}$ increment in baseline range is $\mathrm{OR}(30)=\exp (30 \mathrm{x} 0.0267)=2.23$. This indicates that for every $30 \mathrm{bpm}$ increment in the baseline range, the risk of acidosis increases 2.23fold. A 100 beats increment in the total deceleration area multiplied the risk of acidosis by 1.268 [1.023 - 1.582]. The LTI multiplied the risk of acidosis by $1.053[1.026-1.082]$ per unit increment, and doubled the risk (OR: 2.017 [1.369 - 2.974]) for a 15 bpm difference. In contrast, the STV II was a protective factor; for a $15 \mathrm{bpm}$ difference, the risk of acidosis was roughly halved (OR: $0.463[0.313-0.681])$.

\section{DISCUSSION}

Our present results identified risk factors (both clinical factors and FHR-related factors derived from the LW AAM) for fetal acidosis. In line with the literature data, our results showed that nulliparity ${ }^{42-45}$, late term, and a male fetus ${ }^{42}$ are independent risk factors for fetal acidosis. Our multivariate model took account of the time interval between the end of recording and delivery, corresponding either to the start of the pushing phase (when then FHR signal is not analyzed) or the performance of a caesarean section. This time interval appears to be risk factor for fetal acidosis - especially for vaginal deliveries. Indeed, for non-operative vaginal deliveries, the time interval was longer among cases than among controls. Likewise, acidosis is more frequent in operative vaginal deliveries, and the time interval was shorter. This was in line with a visual analysis of the FHR; it is known that the FHR during expulsion is linked to acidosis ${ }^{46}$. In fact, the second phase of labor is known to increase levels of fetal stress ${ }^{47}$. We chose to not analyse the FHR during pushing because the quality of an externally recorded FHR signal is often poor during 
the second phase of labor ${ }^{48}$, and possible confusion between the FHR and the maternal heart rate 49.

In addition to this parameter, other FHR-related variables generated by the AAM during the first phase of labor also appear to be independent predictive factors for acidosis. In our multivariate model, the "late deceleration area" variable appears (in light of the other deceleration variables) to be the most relevant for predicting acidosis. Cahill et al. ${ }^{50,51}$ noted that the total deceleration area (rather the late deceleration area) is a risk factor for acidosis. The distinction between late/early/variable decelerations is probably not useful because the latest evidence indicates that all the decelerations have the same physiological mechanism ${ }^{52,53}$. The baseline range and the difference between the mean baseline and the mean FHR also appear to be risk factors for the acidosis, and reflect baseline change or transition to bradycardia / tachycardia. In line with the literature data ${ }^{10}$, we found that signal stability criteria are linked to acidosis. However, the presence of zones with an unassignable baseline was not an independent risk factor in our multivariate model. In contrast, the model showed that the MEV was an independent risk factor for acidosis; the lower the MEV, the greater the likelihood of decelerations.

Certain variability parameters (LTI and STV II) also appear to be predictive factors for fetal acidosis. Few studies have highlighted the importance of these conventional variables, and so this finding must be confirmed in further work. Although our univariate analyses revealed significant differences in the four spectral power bands, these variables were not independent risk factors in our multivariate model. It is acknowledged that a fall in the $\mathrm{P}_{\mathrm{HF}}$ or $\mathrm{P}_{\mathrm{MF}}$ parameter is predictive of acidosis ${ }^{54}$ both before and during delivery ${ }^{55,56}$; $\mathrm{P}_{\mathrm{HF}}$ and $\mathrm{P}_{\mathrm{MF}}$ are supposedly indices of variability ${ }^{2}$. Our results for these indices appear to be contradictory (like those of ${ }^{55}$ ) because all four were higher in cases of acidosis. We hypothesize that the four indices increased during decelerations, which are more frequent in cases of acidosis. Even though most of the spectrogram of a deceleration signal contains lower frequencies, there is a small proportion of high frequencies. 
However, the amplitude of the "variability signal" is generally much smaller than that of a deceleration. Consequently, the high-frequency part of the deceleration is not negligible, relative to a variability signal. Furthermore, the low variability periods were short (accounting for 10 to 20 minutes of the 120-minute recording) and did not greatly influence the recording's overall mean variability. Lastly, most of the cases of acidosis observed in the present study were moderate, and there were few cases of severe metabolic acidosis (associated with low variability). In contrast, the results of major retrospective and prospective clinical studies ${ }^{50,57}$ do not agree with some of the cardiotocography's main guiding principles. For example, most fetuses with acidemia display an increase in FHR variability, rather than a reduction ${ }^{50,57-60}$ as in the present study.

The HFVI, via changes in the activity of the autonomic nervous system, might therefore decrease in the event of fetal hypoxia $(\mathrm{pHa}<7.15){ }^{37}$ but, as with the power variables, the HFVI was not an independent risk factor in our multivariate model. The HFVI and STV II are indices of variability that are normalized by the standard deviation of the signal, and thus decrease during decelerations - confirming our univariate analyses. Hence, it is difficult to know whether the indices' value in predicting acidosis is related to the deceleration, or the absence of variability in the recording. We decided to include both morphological and frequency-related variables in our model; the relevance of this conjoint analysis can be challenged, although each type of parameter provides useful information.

The implementation of large, well-structured data warehouse enabled us to perform clinical research on a rare but debilitating pathology. One major strength of our study database is the absence of missing clinical data on the mother or the newborn. The quality of the FHR recordings (lasting for at least $120 \mathrm{~min})$ is very high, and the level of signal loss $(\sim 5 \%)$ is low. The cord blood samples met the recommended quality criteria ${ }^{20}$. Furthermore, our study covered a large number of clinical variables (apart from smoking and fever) and over 40 FHR-derived variables generated by the AAM. It should be noted that the frequency of neonatal acidosis in our data warehouse is 
the same as in the literature, i.e. $0.5 \%$ of term births have a pHa below $7^{61}$, and about $3 \%$ have a pHa below $7.10^{43,62}$. This was a single-center study; building a high-quality data warehouse would be more difficult in a multicenter study. Furthermore, a multicenter study could increase the number of cases but would also induce treatment bias related to intercenter differences in the frequency of non-scheduled caesarean sections. The optimal caesarean section rate (for reducing the frequency of invasive obstetric procedures without increasing neonatal morbidity and mortality rates) is reportedly around $10-15 \%{ }^{63}$; this rate is in line with obstetrical practice in our center (14\%, in 2017) and elsewhere in France (ranging from $14.5 \%$ to $28.9 \%$ in hospitals with a NICU $\left.{ }^{64}\right)$.

\section{Limitations}

This threshold to define acidosis (also used by other researchers ${ }^{65-69}$ yielded a sufficient number of cases $(\mathrm{n}=381)$. A lower $\mathrm{pH}$ threshold would result in a smaller the number of cases (53 observations for $\mathrm{pH}<7.05$, and 21 for $\mathrm{pH}<7.00$ ); excluding cases of respiratory acidosis means that the FHR recording before pushing is more likely to reflect metabolic acidosis. In view of the large number of initial variables and a low number of observations for cases with the lowest $\mathrm{pH}$ value, our statistical model would lack power and robustness ${ }^{70}$. Some researchers have selected a pHa threshold $\leq 7.05$ ( $n=7$ cases in the series by ${ }^{71}$ and $n=15$ cases in the series by ${ }^{72}$ ) because it is associated with elevated fetal and neonatal morbidity and mortality ${ }^{19}$. Jeżewski et al. and Czabanski et al. ${ }^{26,73}$ selected a higher threshold $(\mathrm{pH}<7.20)$. There is no consensus on the threshold that can optimally distinguish between favorable or unfavorable neonatal outcomes. Some researchers have chosen to combine the pHa criterion with the base deficit (BD) ${ }^{74}$; this provides information on metabolic acidosis. Using the $\mathrm{BD}$ (and not the $\mathrm{pH}$ ) as the case criterion is not as straightforward as it seems. In fact, the different parameters ( $\mathrm{BD}_{\text {blood }}$ and $\mathrm{BD}_{\text {ecf }}$ ) are calculated from the $\mathrm{pH}$ and $\mathrm{pCO}_{2}$ values. Likewise, analyzers can also give disparate results because they use different algorithms to calculate $\mathrm{BD}_{\text {blood }}{ }^{75}$. In principal, Clinical and Laboratory 
Standards Institute standards should be used ${ }^{76}$. The umbilical artery blood lactate concentration can be used to quantify metabolic acidosis, and values exceeding $10 \mathrm{mmol} / \mathrm{L}$ have been strongly associated with adverse short-term outcomes in newborns ${ }^{77}$. Furthermore, analyzers are often calibrated differently or measure lactate concentrations in different blood compartments; hence, reference values may vary according to the device ${ }^{78}$. Other researchers have preferred to apply compound endpoints that include the neonatal condition. However, it is easier to study a single criterion than a compound endpoint for which interpretation of the neonatal clinical criteria may vary.

Cases in which the $\mathrm{pH}$ at birth was between 7.15 and 7.25 were not taken into account in this analysis, in order to obtain a true contrast between the two groups; this may have overestimated the results for the AUC.

Our FHR analysis covered a period of 120 minutes before the start of pushing or the decision to perform a caesarean section during labor; this period appears to be sufficiently long for an objective analysis. The FHR recordings were all reviewed by an expert in FHR analysis, and the quality of the signal was optimal - reducing signal loss and improving the automated analysis of the FHR ${ }^{79}$. In contrast, this exclusion may constitute a limitation relative to "real-life" routine obstetric practice.

Furthermore, the dataset included a mixture of internal and external FHR acquisition modes; the mode is known to have a significant influence on the computation of FHR indices ${ }^{80}$.

\section{CONCLUSION}

Although clinical parameters (such as nulliparity, term and a male fetus) are predictive of the risk of fetal acidosis, automated FHR analysis identified additional factors: the baseline range, the FHR instability, and the total area for late decelerations. The results of our multivariate model offer high discriminant power (AUC=0.79). Our future work will address (i) the prediction of the risk of fetal acidosis using a new AAM that would approach the expert consensus performance 
and (ii) the implementation of a predictive score or an obstetric decision support tool for the prevention of fetal acidosis, as our database grows over time. The idea is to focus the clinician's attention on parameters such as the baseline range and the late deceleration area as a guide to obstetrical decision-making when the recording is difficult to interpret by an expert.

\section{REFERENCES}

1. Low JA, Panagiotopoulos C, Derrick EJ. Newborn complications after intrapartum asphyxia with metabolic acidosis in the term fetus. Am J Obstet Gynecol 1994;170(4):1081-7.

2. Ayres-de-Campos D, Spong CY, Chandraharan E. FIGO consensus guidelines on intrapartum fetal monitoring: Cardiotocography. Int J Gynecol Obstet 2015;131(1):13-24.

3. Trimbos J, Keirse M. Observer variability in assessment of antepartum cardiotocograms. BJOG Int J Obstet Gynaecol 1978;85(12):900-6.

4. Lotgering FK, Wallenburg HC, Schouten HJ. Interobserver and intraobserver variation in the assessment of antepartum cardiotocograms. Am J Obstet Gynecol 1982;144(6):701-5.

5. Nielsen PV, Stigsby B, Nickelsen C, Nim J. Intra- and inter-observer variability in the assessment of intrapartum cardiotocograms. Acta Obstet Gynecol Scand 1987;66(5):421-4.

6. Bernardes J, Moura C, de Sa JP, Leite LP. The Porto system for automated cardiotocographic signal analysis. J Perinat Med 1991;19(1-2):61-5.

7. Dawes GS, Moulden M, Redman CW. System 8000: computerized antenatal FHR analysis. J Perinat Med 1991;19(1-2):47-51.

8. Ayres-de-Campos D, Bernardes J, Garrido A, Marques-de-Sá J, Pereira-Leite L. SisPorto 2.0: a program for automated analysis of cardiotocograms. J Matern Fetal Med 2000;9(5):311-8.

9. Magenes G, Signorini M, Ferrario M, Lunghi F. 2CTG2: A new system for the antepartum analysis of fetal heart rate. Springer; 2007. p. 781-4.

10. Georgieva A, Payne SJ, Moulden M, Redman CWG. Computerized fetal heart rate analysis in labor: detection of intervals with un-assignable baseline. Physiol Meas 2011;32(10):1549-60.

11. De Haan J, Van Bemmel JH, Stolte LAM, et al. Quantitative evaluation of fetal heart rate patterns: III. Beat-to-beat arrhythmia. Eur J Obstet Gynecol 1971;1(4):137-146.

12. Siira SM, Ojala TH, Vahlberg TJ, et al. Marked fetal acidosis and specific changes in power spectrum analysis of fetal heart rate variability recorded during the last hour of labour. BJOG Int J Obstet Gynaecol 2005;112(4):418-23.

13. van Laar J, Peters C, Vullings R, Houterman S, Bergmans J, Oei S. Fetal autonomic response to severe acidaemia during labour. BJOG Int J Obstet Gynaecol 2010;117(4):429-37.

14. Houzé de l'Aulnoit A, Boudet S, Demailly R, Peyrodie L, Beuscart R, Houzé de l'Aulnoit D. Baseline fetal heart rate analysis: Eleven automatic methods versus expert consensus. IEEE; 2016. p. 3576-81. 
15. Houzé de l'Aulnoit A, Boudet S, Demailly R, et al. Automated fetal heart rate analysis for baseline determination and acceleration/deceleration detection: A comparison of 11 methods versus expert consensus. Biomed Signal Process Control 2019;49:113-23.

16. Lu Y, Wei S. Nonlinear baseline estimation of FHR signal using empirical mode decomposition. IEEE; 2012. p. 1645-9.

17. Leroy B, Lefort F. A propos du poids et de la taille des nouveau-nés à la naissance. Rev Fr Gynecol 1971;66(6-7):391-6.

18. Apgar V. A proposal for a new method of evaluation of the newborn. Class Pap Crit Care 1952;32(449):97.

19. Victory R, Penava D, da Silva O, Natale R, Richardson B. Umbilical cord $\mathrm{pH}$ and base excess values in relation to adverse outcome events for infants delivering at term. Am J Obstet Gynecol 2004;191(6):2021-2028.

20. Westgate J, Garibaldi JM, Greene KR. Umbilical cord blood gas analysis at delivery: a time for quality data. Br J Obstet Gynaecol 1994;101(12):1054-63.

21. Rooth G, Huch A, Huch R. FIGO News: guidelines for the use of fetal monitoring. Int J Gynecol Obstet 1987;25:159-67.

22. Pardey J, Moulden M, Redman CWG. A computer system for the numerical analysis of nonstress tests. Am J Obstet Gynecol 2002;186(5):1095-103.

23. Bernardes J, Ayres-de-Campos D, Costa-Pereira A, Pereira-Leite L, Garrido A. Objective computerized fetal heart rate analysis. Int J Gynaecol Obstet Off Organ Int Fed Gynaecol Obstet 1998;62(2):141-7.

24. Magenes G, Signorini M, Sassi R, Arduini D. Multiparametric analysis of fetal heart rate: comparison of neural and statistical classifiers. IFMBE; 2001. p. 360-3.

25. Gonçalves H, Bernardes J, Paula Rocha A, Ayres-de-Campos D. Linear and nonlinear analysis of heart rate patterns associated with fetal behavioral states in the antepartum period. Early Hum Dev 2007;83(9):585-91.

26. Jezewski M, Czabański R, Wróbel J, Horoba K. Analysis of extracted cardiotocographic signal features to improve automated prediction of fetal outcome. Biocybern Biomed Eng 2010;30(4):2947.

27. Jezewski J, Wrobel J, Horoba K. Comparison of Doppler ultrasound and direct electrocardiography acquisition techniques for quantification of fetal heart rate variability. IEEE Trans Biomed Eng 2006;53(5):855-64.

28. van Geijn HP, Jongsma HW, de Haan J, Eskes TK. Analysis of heart rate and beat-to-beat variability: Interval difference index. Am J Obstet Gynecol 1980;138(3):246-52.

29. Signorini MG, Magenes G, Cerutti S, Arduini D. Linear and nonlinear parameters for the analysis of fetal heart rate signal from cardiotocographic recordings. IEEE Trans Biomed Eng 2003;50(3):36574.

30. Gonçalves H, Rocha AP, Ayres-de-Campos D, Bernardes J. Linear and nonlinear fetal heart rate analysis of normal and acidemic fetuses in the minutes preceding delivery. Med Biol Eng Comput 2006;44(10):847-55. 
31. Heart rate variability: standards of measurement, physiological interpretation and clinical use. Task Force of the European Society of Cardiology and the North American Society of Pacing and Electrophysiology. Circulation 1996;93(5):1043-65.

32. Ohta T, Okamura K, Kimura Y, et al. Alteration in the Low-Frequency Domain in Power Spectral Analysisof Fetal Heart Beat Fluctuations. Fetal Diagn Ther 1999;14(2):92-7.

33. Gonçalves H, Costa A, Ayres-de-Campos D, Costa-Santos C, Rocha AP, Bernardes J. Comparison of real beat-to-beat signals with commercially available $4 \mathrm{~Hz}$ sampling on the evaluation of foetal heart rate variability. Med Biol Eng Comput 2013;51(6):665-76.

34. David M, Hirsch M, Akselrod S. Maturation of fetal cardiac autonomic control as expressed by fetal heart rate variability. IEEE; 2006. p. 901-4.

35. Karin J, Hirsch M, Sagiv C, Akselrod S. Fetal autonomic nervous system activity monitoring by spectral analysis of heart rate variations. IEEE; 1992. p. 479-82.

36. Oppenheimer LW, Lewinsky RM. Power spectral analysis of fetal heart rate. Baillières Clin Obstet Gynaecol 1994;8(3):643-61.

37. Logier R, De Jonckheere J, Jeanne M, Matis R. Fetal distress diagnosis using heart rate variability analysis: design of a high frequency variability index. In: Engineering in Medicine and Biology Society, 2008. EMBS 2008. 30th Annual International Conference of the IEEE. IEEE; 2008. p. 47284731.

38. Bastien P, Vinzi VE, Tenenhaus M. PLS generalised linear regression. Comput Stat Data Anal 2005;48(1):17-46.

39. Wehrens R, Mevik B-H. The pls package: principal component and partial least squares regression in R. 2007;

40. Liquet B, de Micheaux PL, Hejblum BP, Thiébaut R. Group and sparse group partial least square approaches applied in genomics context. Bioinformatics 2015;32(1):35-42.

41. Hosmer Jr DW, Lemeshow S, Sturdivant RX. Applied logistic regression. John Wiley \& Sons; 2013.

42. Heinonen S, Saarikoski S. Reproductive risk factors of fetal asphyxia at delivery: a population based analysis. J Clin Epidemiol 2001;54(4):407-10.

43. Sabol BA, Caughey AB. Acidemia in neonates with a 5-minute Apgar score of 7 or greater-What are the outcomes? Am J Obstet Gynecol 2016;215(4):486-e1.

44. Ramanah R, Omar S, Guillien A, et al. Predicting umbilical artery pH during labour: Development and validation of a nomogram using fetal heart rate patterns. Eur J Obstet Gynecol Reprod Biol 2018;225:166-71.

45. Crovetto F, Fumagalli M, De Carli A, et al. Obstetric risk factors for poor neonatal adaptation at birth. J Matern Fetal Neonatal Med 2018;31(18):2429-35.

46. Melchior J, Cavagna J, Bernard N. Le rythme cardiaque fotal pendant l'expulsion de l'accouchement normal. Médecine Périnatale 1977;6:225-32.

47. Armstrong L, Stenson B. Use of umbilical cord blood gas analysis in the assessment of the newborn. Arch Dis Child-Fetal Neonatal Ed 2007;92(6):F430-4. 
48. Nunes I, Ayres-de-Campos D, Costa-Santos C, Bernardes J. Differences between external and internal fetal heart rate monitoring during the second stage of labor: a prospective observational study. J Perinat Med 2014;42(4):493-498.

49. Neilson DR, Freeman RK, Mangan S. Signal ambiguity resulting in unexpected outcome with external fetal heart rate monitoring. Am J Obstet Gynecol 2008;198(6):717-24.

50. Cahill AG, Tuuli MG, Stout MJ, López JD, Macones GA. A prospective cohort study of fetal heart rate monitoring: deceleration area is predictive of fetal acidemia. Am J Obstet Gynecol 2018;218(5):523-e1.

51. Marti Gamboa S, Lapresta Moros M, Pascual Mancho J, Lapresta Moros C, Castán Mateo S. Deceleration area and fetal acidemia. J Matern Fetal Neonatal Med 2017;30(21):2578-84.

52. Lear CA, Galinsky R, Wassink G, et al. The myths and physiology surrounding intrapartum decelerations: the critical role of the peripheral chemoreflex. J Physiol 2016;594(17):4711-25.

53. Sholapurkar SL. Myths at the core of Intrapartum Cardiotocography Interpretation-Risks of false Ideology, Prospect theory and way forward. Clin Obstet Gynecol 2019;5:1-9.

54. Van Laar JOEH, Porath MM, Peters CHL, Oei SG. Spectral analysis of fetal heart rate variability for fetal surveillance: review of the literature. Acta Obstet Gynecol Scand 2008;87(3):300-6.

55. Warrick PA, Hamilton EF. Fetal heart-rate variability response to uterine contractions during labour and delivery. IEEE; 2012. p. 417-20.

56. Chung DY, Sim YB, Park KT, Yi SH, Shin JC, Kim SP. Spectral analysis of fetal heart rate variability as a predictor of intrapartum fetal distress. Int J Gynaecol Obstet Off Organ Int Fed Gynaecol Obstet 2001;73(2):109-16.

57. Cahill AG, Roehl KA, Odibo AO, Macones GA. Association of atypical decelerations with acidemia. Obstet Gynecol 2012;120(6):1387-93.

58. Nunes I, Ayres-de-Campos D, Kwee A, Rosén KG. Prolonged saltatory fetal heart rate pattern leading to newborn metabolic acidosis. Clin Exp Obstet Gynecol 2014;41(5):507-11.

59. Georgieva A, Abry P, Chudáček V, et al. Computer-based intrapartum fetal monitoring and beyond: a review of the 2nd Workshop on Signal Processing and Monitoring in Labor (Oct 2017, Oxford UK). Acta Obstet Gynecol Scand 2019;

60. Lu K, Holzmann M, Abtahi F, Lindecrantz K, Lindqvist PG, Nordstrom L. Fetal heart rate short term variation during labor in relation to scalp blood lactate concentration. Acta Obstet Gynecol Scand 2018;97(10):1274-80.

61. CNGOF. Recommandations pour la pratique clinique: Modalités de surveillance foetale pendant le travail. 2007.

62. Fournié A, Connan L, Parant O, Lesourd-Pontonnier F. Souffrance fœtale aiguë. Encycl Méd Chir. $1999 ; 11 \mathrm{p}$.

63. Moore B. Appropriate technology for birth. The Lancet 1985;326(8458):787.

64. Rudigoz RC, Milliez J, Ville Y, Crépin G. De la bientraitance en obstétrique. La réalité du fonctionnement des maternités. Bull Académie Natl Médecine 2018. 
65. Nielsen PV, Stigsby B, Nickelsen C, Nim J. Computer assessment of the intrapartum cardiotocogram. II. The value of compared with visual assessment. Acta Obstet Gynecol Scand 1988;67(5):461-4.

66. Chung TK, Mohajer MP, Yang ZJ, Chang AM, Sahota DS. The prediction of fetal acidosis at birth by computerised analysis of intrapartum cardiotocography. Br J Obstet Gynaecol 1995;102(6):454-60.

67. Salamalekis E, Thomopoulos P, Giannaris D, et al. Computerised intrapartum diagnosis of fetal hypoxia based on fetal heart rate monitoring and fetal pulse oximetry recordings utilising wavelet analysis and neural networks. BJOG Int J Obstet Gynaecol 2002;109(10):1137-42.

68. Georgoulas GG, Stylios CD, Nokas G, Groumpos PP. Classification of fetal heart rate during labour using hidden Markov models. IEEE; 2004. p. 2471-5.

69. Spilka J, Chudáček V, Koucký M, et al. Using nonlinear features for fetal heart rate classification. Biomed Signal Process Control 2012;7(4):350-7.

70. Peduzzi P, Concato J, Kemper E, Holford TR, Feinstein AR. A simulation study of the number of events per variable in logistic regression analysis. J Clin Epidemiol 1996;49(12):1373-9.

71. Costa A, Ayres-de-Campos D, Costa F, Santos C, Bernardes J. Prediction of neonatal acidemia by computer analysis of fetal heart rate and ST event signals. Am J Obstet Gynecol 2009;201(5):464-e1.

72. Doret M, Spilka J, Chudáček V, Gonçalves P, Abry P. Fractal Analysis and Hurst Parameter for Intrapartum Fetal Heart Rate Variability Analysis: A Versatile Alternative to Frequency Bands and LF/HF Ratio. PLOS ONE 2015;10(8):e0136661.

73. Czabanski R, Jezewski J, Matonia A, Jezewski M. Computerized analysis of fetal heart rate signals as the predictor of neonatal acidemia. Expert Syst Appl 2012;39(15):11846-60.

74. Ayres-de-Campos D, Ugwumadu A, Banfield P, et al. A randomised clinical trial of intrapartum fetal monitoring with computer analysis and alerts versus previously available monitoring. BMC Pregnancy Childbirth 2010;10(1):71.

75. Mokarami P, Wiberg N, Olofsson P. An overlooked aspect on metabolic acidosis at birth: blood gas analyzers calculate base deficit differently. Acta Obstet Gynecol Scand 2012;91(5):574-9.

76. CLSI. Blood gas and $\mathrm{pH}$ analysis and related measurements; approved guidelines. C46-A2 Second edition. Wayne, PA: Clinical and Laboratory Standards Institute 2009;

77. Wiberg N, Källén K, Herbst A, Olofsson P. Relation between umbilical cord blood pH, base deficit, lactate, 5-minute Apgar score and development of hypoxic ischemic encephalopathy. Acta Obstet Gynecol Scand 2010;89(10):1263-9.

78. Nordström L. Fetal scalp and cord blood lactate. Best Pract Res Clin Obstet Gynaecol 2004;18(3):467-76.

79. Pinto P, Costa-Santos C, Gonçalves H, Ayres-De-Campos D, Bernardes J. Improvements in fetal heart rate analysis by the removal of maternal-fetal heart rate ambiguities. BMC Pregnancy Childbirth. 2015;15(1).

80. Gonçalves H, Rocha AP, Ayres-de-Campos D, Bernardes J. Internal versus external intrapartum foetal heart rate monitoring: the effect on linear and nonlinear parameters. Physiol Meas 2006;27(3):307-19. 
81. Georgoulas G, Stylios D, Groumpos P. Predicting the risk of metabolic acidosis for newborns based on fetal heart rate signal classification using support vector machines. IEEE Trans Biomed Eng 2006;53(5):875-84.

82. Ayres-de-Campos D, Sousa P, Costa A, Bernardes J. Omniview-SisPorto® 3.5-a central fetal monitoring station with online alerts based on computerized cardiotocogram + ST event analysis. J Perinat Med 2008;36(3):260-4.

83. Cesarelli $\mathrm{M}$, Romano $\mathrm{M}$, Bifulco $\mathrm{P}$. Comparison of short term variability indexes in cardiotocographic foetal monitoring. Comput Biol Med 2009;39(2):106-18.

84. Parer J. Experimental studies of fetal asphyxia and fetal heart rate interpretation. In: Research in perinatal medicine. Perinatology Press, Ithaca, New York; 1984. p. 113-69.

85. Holzmann M, Wretler S, Cnattingius S, Nordström L. Cardiotocography patterns and risk of intrapartum fetal acidemia. J Perinat Med 2015;43(4):473-9.

86. Ball RH, Parer JT. The physiologic mechanisms of variable decelerations. Am J Obstet Gynecol 1992;166(6):1683-9.

87. Arduini D, Rizzo G, Romanini C. Computerized analysis of fetal heart rate. J Perinat Med 1994;22 Suppl 1:22-7.

88. Magenes G, Signorini MG, Arduini D. Classification of cardiotocographic records by neural networks. IEEE; 2000. p. 637-41 vol.3.

89. Georgoulas G, Stylios C, Groumpos P. Feature extraction and classification of fetal heart rate using wavelet analysis and Support Vector Machines. Int J Artif Intell Tools 2006;15(03):411-32.

90. Spilka, J. (2013). Complex approach to fetal heart rate analysis: A hierarchical classification model. Czech Technical University, Faculty of Electrical Engineering, Prague, 35-47.

91. Electrophysiology TF of the ES of C the NAS of P. Heart rate variability: standards of measurement, physiological interpretation, and clinical use. Circulation 1996;93(5):1043-65.

92. Chudáček V, Spilka J, Janků P, Koucký M, Lhotská L, Huptych M. Automatic evaluation of intrapartum fetal heart rate recordings: a comprehensive analysis of useful features. Physiol Meas 2011;32(8):1347-60.

93. Liu, M., Shen, Y., \& Scerbo, M. (2008). A Survey of Computerized Fetal Heart Rate Monitoring and Interpretation Techniques. In 2008 Modeling and Simulation Capstone Conference (pp. 1-8).

94. Romano M, Iuppariello L, Ponsiglione AM, Improta G, Bifulco P, Cesarelli M. Frequency and time domain analysis of foetal heart rate variability with traditional indexes: a critical survey. Comput Math Methods Med 2016;2016.

95. Garabedian C, Butruille L, Servan-Schreiber E, et al. Fetal heart-rate variability: validation of a new continuous, noninvasive computerized analysis. Gynecol Obstet Invest 2017;82(5):500-7.

\section{SUPPLEMENTARY MATERIALS}


Agathe HOUZE de l'AULNOIT- v2

1 Table S1. FHR-related data

2

\begin{tabular}{|c|c|c|c|c|c|c|}
\hline & Variable & Description & Type & $\begin{array}{l}\text { Coding or } \\
\text { unit }\end{array}$ & $\begin{array}{l}\text { Behavior } \\
\text { expected in the } \\
\text { event of } \\
\text { acidosis }\end{array}$ & References \\
\hline \multirow{3}{*}{ Characteristics } & Total time in labour & Duration of labor, in minutes & $\mathrm{N}$ & $\min _{\min }$ & & \\
\hline & $\begin{array}{l}\text { Time interval between the end of the FHR recording and } \\
\text { birth }\end{array}$ & Time interval between the end of the FHR recording and birth & $\mathrm{N}$ & $\min$ & & \\
\hline & Signal loss & Percentage time with loss of signal & $\mathrm{N}$ & $\%$ & & \\
\hline \multirow{6}{*}{$\begin{array}{l}\text { FHR and signal } \\
\text { stability }\end{array}$} & Signal stability index x 100 & $\begin{array}{l}\text { Signal stability index (x 100) } \\
\text { The lower the SSI, the less often the FHR is at baseline and the } \\
\text { more likely it is to be abnormal }\end{array}$ & $\mathrm{N}$ & $\mathrm{bpm}^{-1}$ & \multirow{4}{*}{$\begin{array}{l}\downarrow \\
\downarrow \\
\uparrow \\
\uparrow\end{array}$} & \multirow[t]{4}{*}{10} \\
\hline & Minimum expected value MEV & $\begin{array}{l}\text { Minimum expected value } \\
\text { The lower the MEV, the more the FHR falls to the nadir of the } \\
\text { decelerations and the more likely it is to be abnormal }\end{array}$ & $\mathrm{N}$ & bpm & & \\
\hline & Presence of an unassignable baseline in the null zone & $\begin{array}{l}\text { Presence of unassignable baseline in the null zone (defined as } \\
\mathrm{SSI}<0.022 \text { and } \mathrm{MEV}<70 \mathrm{bpm})\end{array}$ & $\mathrm{F}$ & yes / no & & \\
\hline & $\begin{array}{l}\text { Presence of an unassignable baseline in the intermediate } \\
\text { zone }\end{array}$ & $\begin{array}{l}\text { Presence of unassignable baseline in the intermediate zone } \\
\text { (defined as SSI }<0.048 \text { and } \mathrm{MEV}<86 \mathrm{bpm} \text { ) }\end{array}$ & $\mathrm{F}$ & yes / no & & \\
\hline & FHR range & $\begin{array}{l}\text { Maximum FHR - minimum FHR in the FHR recording, apart } \\
\text { from } A / D\end{array}$ & $\mathrm{~N}$ & bpm & $\uparrow$ & 8,81 \\
\hline & Standard deviation of the FHR & Standard deviation of the FHR, including the A/D & $\mathrm{N}$ & bpm & $\uparrow$ & 30,82,83 \\
\hline \multirow{6}{*}{ Baseline } & Mean baseline - mean FHR & Mean baseline - mean FHR in the recording & $\mathrm{N}$ & bpm & $\uparrow$ & \\
\hline & Time during which the baseline was below $110 \mathrm{bpm}$ & Percentage of time during which the baseline is below $110 \mathrm{bpm}$ & $\mathrm{N}$ & $\%$ & $\uparrow$ & \\
\hline & Time during which the baseline above $160 \mathrm{bpm}$ & Percentage of time during which the baseline is above $160 \mathrm{bpm}$ & $\mathrm{N}$ & $\%$ & $\uparrow$ & \\
\hline & Baseline area below $110 \mathrm{bpm}$ & $\begin{array}{l}\text { When the baseline is }<110 \mathrm{bpm} \text {, the number of missed beats } \\
\text { relative to a constant rate at } 110 \mathrm{bpm}\end{array}$ & $\mathrm{N}$ & beats & $\uparrow$ & \\
\hline & Baseline area above $160 \mathrm{bpm}$ & $\begin{array}{l}\text { When the baseline is > à } 160 \mathrm{bpm} \text {, the number of extra beats } \\
\text { relative to a constant rate at } 160 \mathrm{bpm}\end{array}$ & $\mathrm{N}$ & beats & $\uparrow$ & \\
\hline & Baseline range & $\begin{array}{l}\text { Baseline range (max baseline - min baseline) during the } \\
\text { recording }\end{array}$ & $\mathrm{N}$ & bpm & $\uparrow$ & \\
\hline \multirow{2}{*}{ Accelerations } & Total number of accelerations & Number of accelerations & $\mathrm{E}$ & & $\downarrow$ & $\frac{2}{2}$ \\
\hline & Total acceleration area & Total acceleration area & $\mathrm{N}$ & bpm & $\downarrow$ & \\
\hline \multirow{5}{*}{ Decelerations } & Total number of decelerations & Number of decelerations (all types) & E & & $\uparrow$ & 2 \\
\hline & Total deceleration area & Total deceleration area (all types) & $\mathrm{N}$ & beats & $\uparrow$ & \\
\hline & Area: prolonged decelerations (> $180 \mathrm{~s})$ & Total area for prolonged decelerations $(>180 \mathrm{~s})$ & $\mathrm{N}$ & beats & $\uparrow$ & \\
\hline & Area: prolonged decelerations $(>120 \mathrm{~s})$ & Total area for prolonged decelerations $(>120 \mathrm{~s})$ & $\mathrm{N}$ & beats & $\uparrow$ & \\
\hline & Number of early decelerations & Number of early decelerations (caused by compression of the & E & & $\uparrow$ & 2 \\
\hline
\end{tabular}




\section{Agathe HOUZE de l'AULNOIT- v2}

\begin{tabular}{|c|c|c|c|c|c|c|}
\hline & & fetus' head and that do not reflect hypoxia ${ }^{84}$ ) & & & & \\
\hline & Area: early decelerations & Total area for early decelerations & $\mathrm{N}$ & beats & $\uparrow$ & \\
\hline & Numbers of late decelerations & $\begin{array}{l}\text { Number of late decelerations (indicating a chemoreceptor- } \\
\text { mediated response to fetal hypoxemia }{ }^{84,85} \text { ) }\end{array}$ & $\mathrm{E}$ & & $\uparrow$ & 2 \\
\hline & Area: late decelerations & $\begin{array}{l}\text { Total area for late decelerations ( } 8,81 \text {, likely to stimulate } \\
\text { chemoreceptors and indicate hypoxemia) }\end{array}$ & $\mathrm{N}$ & beats & $\uparrow$ & \\
\hline & Number of variable decelerations & $\begin{array}{l}\text { Number of variable decelerations (a baroreceptor response } \\
\text { during compression of the umbilical cord }{ }^{86} \text {, which is rarely } \\
\text { associated with significant hypoxia/fetal acidosis) }\end{array}$ & $\mathrm{E}$ & & $\uparrow$ & 2 \\
\hline & Area: variable decelerations & Total area for variable decelerations & $\mathrm{N}$ & beats & $\uparrow$ & \\
\hline & Presence of repetitive decelerations & $\begin{array}{l}\text { The decelerations are said to be "repetitive" if the ratio } \\
\text { (Number of decelerations / number of contractions) is greater } \\
\text { than } 0.5\end{array}$ & $\mathrm{~F}$ & yes / no & $\uparrow$ & 2 \\
\hline \multirow{5}{*}{$\begin{array}{l}\text { Long-term } \\
\text { variability } \\
\text { (LTV) }\end{array}$} & $\begin{array}{ll}\mathrm{LTV} \\
. \mathrm{LT}\end{array}$ & Change in the LTV & $\mathrm{N}$ & bpm & $\downarrow$ & $\begin{array}{ll}24,25,81 \\
24,25, \ldots \ldots \ldots\end{array}$ \\
\hline & Low LTV $<6$ bpm & Minimum LTV, abnormal < 6 bpm & $\mathrm{N}$ & $\%$ & $\uparrow$ & $\begin{array}{l}\text { Abnormal LTV } \\
\text { OSC.Sil }^{26}\end{array}$ \\
\hline & Marked LTV $>25 \mathrm{bpm}$ & Marked LTV $>25 \mathrm{bpm}$ & $\mathrm{N}$ & $\%$ & $\uparrow$ & OSC.Salt ${ }^{26}$ \\
\hline & Area under the LTV curve $<6 \mathrm{bpm}$ & Area under the LTV curve $<6 \mathrm{bpm}$ & $\mathrm{N}$ & & $\uparrow$ & \\
\hline & LTI & De Haan's long-term irregularity index. & $\mathrm{N}$ & msec & $\downarrow$ & 24-26,80,81 \\
\hline \multirow{5}{*}{$\begin{array}{l}\text { Short-term } \\
\text { variability } \\
\text { (STV) }\end{array}$} & SD STV & Standard deviation of STV & $\mathrm{N}$ & bpm & $\downarrow$ & $26,30,81,82,87,88$ \\
\hline & $\mathrm{STV}<1 \mathrm{bpm}$ & STV below $1 \mathrm{bpm}$, abnormal according to ${ }^{8}$ & $\mathrm{~N}$ & $\%$ & $\uparrow$ & 8 \\
\hline & STV II x 100 & $\begin{array}{l}\text { The STV interval, representing the coefficient of variation for } \\
\text { the difference in STV between consecutive samples. } \\
\text { For scaling reasons, the result is multiplied by } 100 \text {. }\end{array}$ & $\mathrm{N}$ & bpm & $\downarrow$ & $30,88,89$ \\
\hline & STV & Conventional STV & $\mathrm{N}$ & bpm & & $26,30,81,82,87,88$ \\
\hline & STI x 100 & $\begin{array}{l}\text { De Haan's short-term irregularity index. } \\
\text { For scaling reasons, the result is multiplied by } 100 .\end{array}$ & $\mathrm{N}$ & radians & $\uparrow$ & $11,26,27,90$ \\
\hline \multirow{5}{*}{$\begin{array}{l}\text { Frequency- } \\
\text { related }\end{array}$} & $\mathrm{P}_{\mathrm{VLF}} \times 100$ & Power in the very low frequency band $(0.01-0.03 \mathrm{~Hz})(\mathrm{x} 100)$ & $\mathrm{N}$ & $\mathrm{bpm}^{2}$ & $\uparrow \uparrow$ & $29,30,89-92$ \\
\hline & $\mathrm{P}_{\mathrm{LF}} \times 100$ & Power in the low frequency band $(0.03-0.15 \mathrm{~Hz})(\mathrm{x} 100)$ & $\mathrm{N}$ & $\mathrm{bpm}^{2}$ & $\uparrow$ & \\
\hline & $\mathrm{P}_{\mathrm{MF}} \times 100$ & Power in the middle frequency band $(0.15-0.50 \mathrm{~Hz})(\mathrm{x} 100)$ & $\mathrm{N}$ & $\mathrm{bpm}^{2}$ & $\downarrow$ & \\
\hline & $\mathrm{P}_{\mathrm{HF}} \mathrm{X} 100$ & Power in the high frequency band $(0.50-1.00 \mathrm{~Hz})(\mathrm{x} 100)$ & $\mathrm{N}$ & $\mathrm{bpm}^{2}$ & $\downarrow$ & \\
\hline & $\mathrm{P}_{\mathrm{LF}} /\left(\mathrm{P}_{\mathrm{MF}}+\mathrm{P}_{\mathrm{HF}}\right)$ ratio & $\mathrm{P}_{\mathrm{LF}} /\left(\mathrm{P}_{\mathrm{MF}}+\mathrm{P}_{\mathrm{HF}}\right)$ ratio & & & $\uparrow$ & \\
\hline Wavelets & High frequency variability index HFVI & High frequency variability index & $\mathrm{N}$ & & $\downarrow$ & $37,93-$ \\
\hline
\end{tabular}


In the case of a binary qualitative variable coded as 0 or 1 , the odds ratio $(\mathrm{OR})$ is equal to $\exp (1 \times \beta)$, where $\beta$ is the variable's logistic regression coefficient. In the case of a quantitative variable, one can calculate an OR per unit as $\exp (1 \mathrm{x} \beta)$. For greater clarity in clinical terms, the effects of continuous FHR-related variates, under the assumption that the logit is linear in the continuous variate, were also expressed by the odd ratio for an increase $\delta$, equal to $\exp (\delta \times \beta)$. OR $=\exp (\delta \times \beta)^{41}$. The increase was chosen as a function of the variable's distribution, by taking account of the difference between the $90^{\text {th }}$ percentile and the $10^{\text {th }}$ percentile.

S3. Discussion about variability

- If the variability falls and there are no A/D, all the parameters (SD STV, STV, STI, LTI, PVLF, $\mathrm{P}_{\mathrm{LF}}, \mathrm{P}_{\mathrm{MF}}, \mathrm{P}_{\mathrm{HF}}$, IVHF, IVHF_numerator, IVHF_denominator) decrease.

- If the variability falls and there are $\mathrm{A} / \mathrm{D}$, none of the indices falls significantly, reflecting the absence of variability:

- SD STV increases but STV and STI do not change.

- LTI increases.

- PVLF and $\mathrm{P}_{\mathrm{LF}}$ increase, as expected; $\mathrm{P}_{\mathrm{MF}}$ and $\mathrm{P}_{\mathrm{HF}}$ decrease slightly but much less than in the absence of A/D.

- IVHF decreases but this is mainly due to the major increase in the denominator (reflecting the presence of A/D) more than the decrease in the numerator (reflecting the absence of variability). 
In conclusion, none of the indices is a measure of variability alone, and independently of the presence of A/D. The A/D even have a greater influence than variability on many of these indices; in fact, the variability measured for signal 1 should be much greater than that measured for signal 3.

FHR recording], it is difficult to establish the respective influences of the variability and the A/D.

To address this issue, we also calculated these indices solely for D-free periods. However, the results of the univariate analysis were the same. It seems that recordings with D generally have FHR fluctuations that increase these indices, even outside D periods. It is difficult to know whether this is due to an increase in variability in the recordings with $\mathrm{D}$ or to poor measurement by the various indices. 
Agathe HOUZE de l'AULNOIT- v2

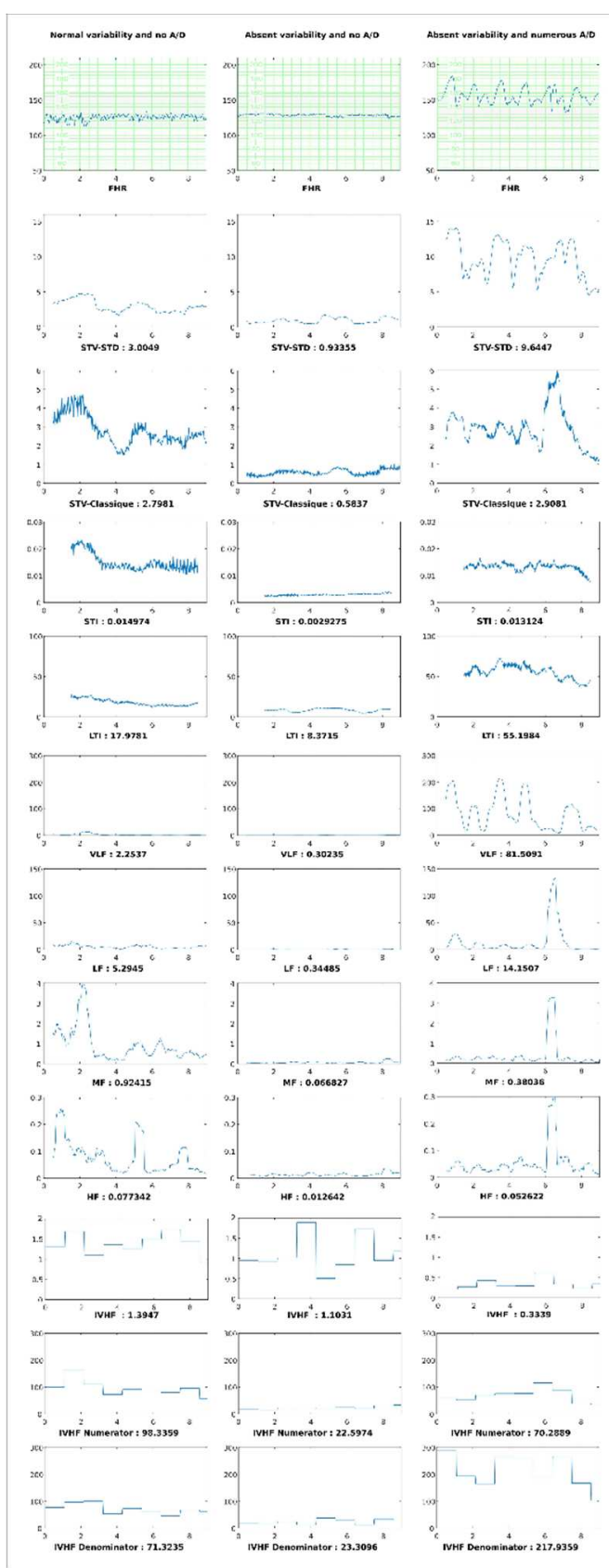


Agathe HOUZE de l'AULNOIT- v2 
- $\geq 22$ weeks of amenorrhoea (WA)

- Live birth

- Vaginal delivery or caesarean during labour

- Mother's age $\geq 18$

- Singleton pregnancy

- Term $\geq 37$ WA

- Non-breech delivery

- Length of the FHR recording $\geq 30$ minutes

$n=8,383$

- $\mathrm{pH}$ data for arterial AND venous blood at birth

- $\quad$ Length of the FHR recording $\geq 120$ minutes

$n=7,334$

- Reliability of the arterial pH data

$n=4,450$

Acidosis

$\mathrm{pH} \leq 7.15$

$n=428$

Intermediate

$7.15<\mathrm{pH}<7.25$

$n=1,717$

Control

pH $\geq 7.25$

$n=2,305$

- Satisfactory FHR signal quality 
Table 1. Clinical variables among cases (acidosis) and controls (no acidosis)

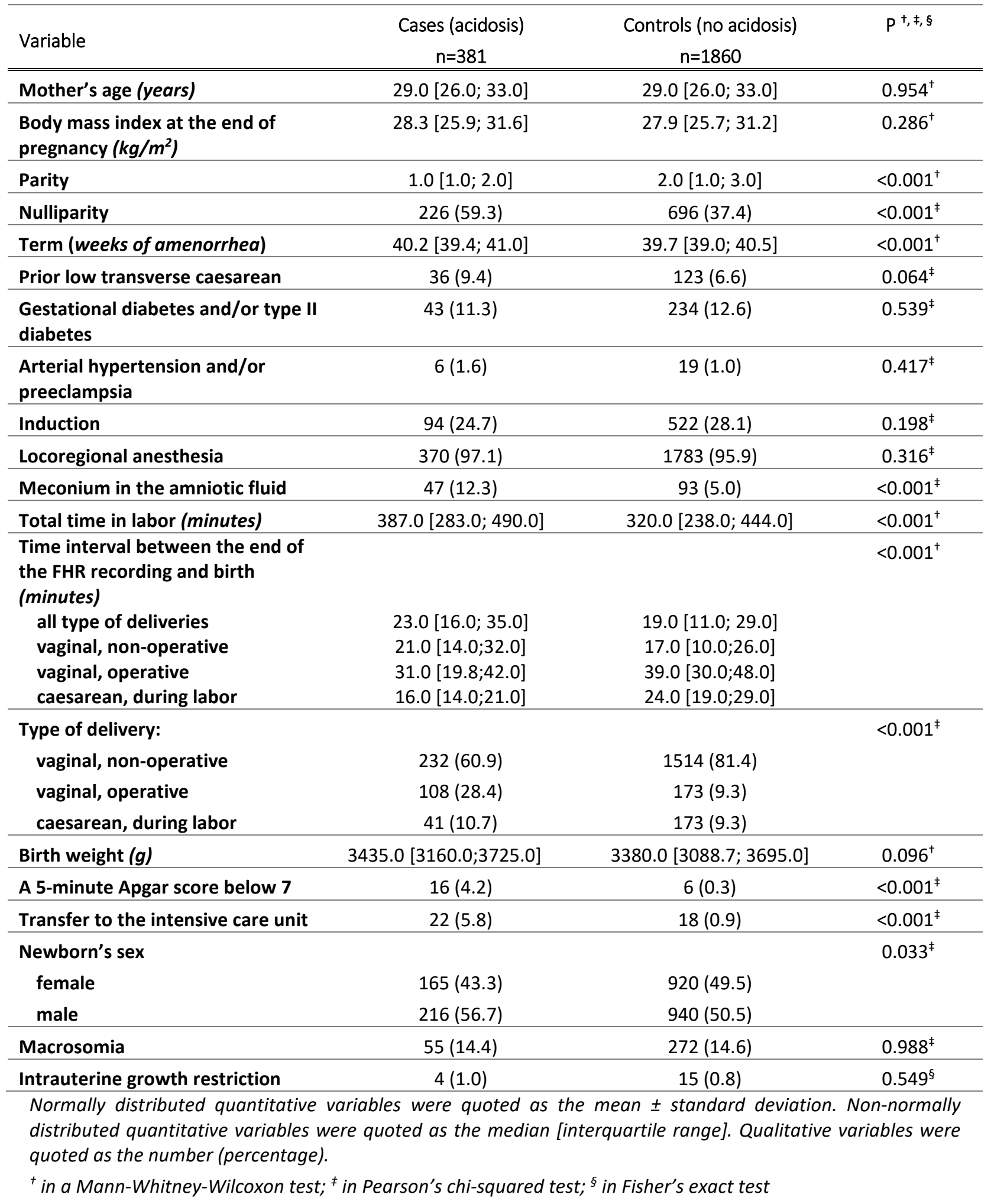

Table 2. Comparison of the morphological FHR variables among cases and controls. 


\begin{tabular}{|c|c|c|c|}
\hline & $\mathrm{n}=381$ & $n=1860$ & \\
\hline Signal loss (\%) & $5.6[3.10 ; 9.80]$ & $4.80[2.18 ; 8.50]$ & $<0.001^{+}$ \\
\hline Signal stability index x 100 & $7.20[5.70 ; 8.80]$ & $8.20[6.80 ; 9.80]$ & $<0.001^{+}$ \\
\hline Minimum expected value MEV (bpm) & $97.95[85.39 ; 108.79]$ & $102.64[92.92 ; 111.46]$ & $<0.001^{+}$ \\
\hline $\begin{array}{l}\text { Presence of an unassignable baseline in the } \\
\text { null zone }\end{array}$ & $108(28.3)$ & $165(8.9)$ & $<0.001^{\neq}$ \\
\hline $\begin{array}{l}\text { Presence of an unassignable baseline in the } \\
\text { intermediate zone }\end{array}$ & $286(75.1)$ & $948(51.0)$ & $<0.001^{\ddagger}$ \\
\hline FHR range (bpm) & $31.00[25.25 ; 38.75]$ & $27.00[22.25 ; 33.00]$ & $<0.001^{+}$ \\
\hline Standard deviation of the FHR (bpm) & $4.76[3.81 ; 5.84]$ & $4.34[3.62 ; 5.16]$ & $<0.001^{+}$ \\
\hline Mean baseline - mean FHR (bpm) & $1.64[0.21 ; 3.12]$ & $0.39[-0.42 ; 1.39]$ & $<0.001^{+}$ \\
\hline \multicolumn{4}{|l|}{ Time during which the baseline was * } \\
\hline - below 110 bpm (\%) & $0.00[0.00 ; 58.30]$ & $0.00[0.00 ; 47.68]$ & $<0.001^{+}$ \\
\hline - above 160 bpm (\%) & $0.00[0.00 ; 100.00]$ & $0.00[0.00 ; 100.00]$ & $<0.001^{+}$ \\
\hline \multicolumn{4}{|l|}{ Baseline area (beats) * } \\
\hline - below 110 bpm & $0.00[0.00 ; 5.53]$ & $0.00[0.00 ; 5.02]$ & $<0.001^{+}$ \\
\hline - above $160 \mathrm{bpm}$ & $0.00[0.00 ; 20.94]$ & $0.00[0.00 ; 24.77]$ & $<0.001^{+}$ \\
\hline Baseline range (bpm) & $31.89[22.11 ; 42.77]$ & $22.60[17.23 ; 30.13]$ & $<0.001^{+}$ \\
\hline Total number of accelerations & $15.00[8.00 ; 23.00]$ & $15.00[9.00 ; 24.00]$ & $0.129^{+}$ \\
\hline Total acceleration area (beats) & $112.10[57.80 ; 181.80]$ & $111.40[58.40 ; 185.40]$ & $0.832^{+}$ \\
\hline Total number of decelerations & $24.00[15.00 ; 33.00]$ & $18.00[11.00 ; 26.00]$ & $<0.001^{+}$ \\
\hline \multicolumn{4}{|l|}{ Numbers of: } \\
\hline prolonged decelerations (>120 s) & $1.00[0.00 ; 2.00]$ & $0.00[0.00 ; 1.00]$ & $<0.001^{+}$ \\
\hline early decelerations & $1.00[0.00 ; 3.00]$ & $1.00[0.00 ; 2.00]$ & $<0.001^{+}$ \\
\hline late decelerations & $2.00[1.00 ; 4.00]$ & $1.00[0.00 ; 2.00]$ & $<0.001^{+}$ \\
\hline variable decelerations & $18.00[11.00 ; 25.00]$ & $14.50[9.00 ; 22.00]$ & $<0.001^{+}$ \\
\hline Total deceleration area (beats) & $333.15[166.21 ; 555.88]$ & $171.36[86.71 ; 295.13]$ & $<0.001^{+}$ \\
\hline \multicolumn{4}{|l|}{ Area (beats): } \\
\hline prolonged decelerations (> $120 \mathrm{~s}$ ) & $38.01[0.10 ; 131.81]$ & $0.00[0.00 ; 42.63]$ & $<0.001^{+}$ \\
\hline prolonged decelerations (> $180 \mathrm{~s}$ ) & $0.00[0.00 ; 32.27]$ & $0.00[0.00 ; 0.00]$ & $<0.001^{+}$ \\
\hline early decelerations & $26.72[0.00 ; 75.63]$ & $9.56[0.00 ; 34.80]$ & $<0.001^{+}$ \\
\hline late decelerations & $40.89[8.27 ; 89.80]$ & $11.61[0.00 ; 36.85]$ & $<0.001^{+}$ \\
\hline variable decelerations & $146.42[80.33 ; 238.61]$ & $99.69[50.97 ; 169.25]$ & $<0.001^{+}$ \\
\hline Presence of repetitive decelerations & $239(62.7)$ & $893(48.0)$ & $<0.001^{\neq}$ \\
\hline \multicolumn{4}{|c|}{$\begin{array}{l}\text { Normally distributed quantitative variables were quoted as the mean } \pm \text { standard deviation. Non-normally } \\
\text { distributed quantitative variables were quoted as the median [interquartile range]. Qualitative variables were } \\
\text { quoted as the number (percentage). }\end{array}$} \\
\hline \multicolumn{4}{|c|}{${ }^{+}$in a Mann-Whitney-Wilcoxon test; ${ }^{*}$ in Pearson's chi-squared test } \\
\hline \multicolumn{4}{|c|}{$\begin{array}{l}\text { * median [minimum; maximum] values are quoted for these variables, the distribution of which was extremely } \\
\text { asymmetric. }\end{array}$} \\
\hline
\end{tabular}

Table 3. The FHR variability variables in the case and control groups

\begin{tabular}{cccc}
\hline Variable & Cases (acidosis) & Controls (no acidosis) & $\mathrm{p}^{+}$ \\
\hline \hline
\end{tabular}




\begin{tabular}{|c|c|c|c|}
\hline Long-term variability (LTV) & & & \\
\hline LTV (bpm) & $14.80[13.07 ; 17.15]$ & 14.59 [12.90;16.63] & 0.131 \\
\hline Low LTV < 6 bpm (\%) & $3.83[0.92 ; 8.36]$ & $3.15[0.99 ; 7.75]$ & 0.337 \\
\hline Marked LTV > 25 bpm (\%) & $6.81[3.88 ; 12.98]$ & $6.30[3.29 ; 10.99]$ & 0.012 \\
\hline $\begin{array}{l}\text { Area under the LTV curve }<6 \mathrm{bpm} \\
(\mathrm{bpm})\end{array}$ & $0.05[0.01 ; 0.10]$ & $0.04[0.01 ; 0.09]$ & 0.345 \\
\hline LTI (msec) & $24.32[20.52 ; 29.93]$ & $22.98[19.24 ; 27.37]$ & $<0.001$ \\
\hline \multicolumn{4}{|l|}{ Short-term variability (STV) } \\
\hline SD STV (bpm) & $4.76[3.81 ; 5.84]$ & $4.34[3.62 ; 5.16]$ & $<0.001$ \\
\hline STV < 1 bpm (\%) & $74.67[68.15 ; 79.99]$ & $76.37[70.35 ; 81.51]$ & 0.001 \\
\hline STV (bpm) & $2.69[2.20 ; 3.21]$ & $2.58[2.13 ; 3.11]$ & $<0.05$ \\
\hline STV II (bpm) x 100 & $20.00[16.38 ; 24.67]$ & $25.40[20.63 ; 30.23]$ & $<0.001$ \\
\hline STI (radians) x 100 & $1.09[0.85 ; 1.38]$ & $1.12[0.89 ; 1.40]$ & 0.233 \\
\hline \multicolumn{4}{|l|}{ Frequency variables } \\
\hline$P_{V L F}\left(b p m^{2}\right) \times 100$ & $13.85[7.79 ; 20.54]$ & $10.74[6.92 ; 16.08]$ & $<0.001$ \\
\hline$P_{L F}\left(b p m^{2}\right) \times 100$ & $9.11[6.04 ; 12.79]$ & $8.15[5.61 ; 11.33]$ & $<0.001$ \\
\hline$P_{M F}\left(b p m^{2}\right) \times 100$ & $1.09[0.76 ; 1.70]$ & $0.96[0.67 ; 1.41]$ & $<0.001$ \\
\hline$P_{H F}\left(b p m^{2}\right) \times 100$ & $0.13[0.09 ; 0.19]$ & $0.12[0.09 ; 0.17]$ & $<0.001$ \\
\hline $\mathrm{P}_{\mathrm{LF}} /\left(\mathrm{P}_{\mathrm{MF}}+\mathrm{P}_{\mathrm{HF}}\right)$ ratio & $6.97[5.43 ; 8.94]$ & $7.06[5.59 ; 8.86]$ & 0.600 \\
\hline High frequency variability index HFVI & $0.96[0.84 ; 1.04]$ & $1.01[0.91 ; 1.08]$ & $<0.001$ \\
\hline
\end{tabular}

Non-normally distributed quantitative variables were quoted as the median [interquartile range]. For scaling reasons, some results are multiplied by 100.

t in a non-parametric Mann-Whitney-Wilcoxon test

LTI: long-term irregularity; II: interval index; SD: standard deviation; STI: short-term irregularity; P: power; VLF: very low frequency (0.01 - $0.03 \mathrm{~Hz})$; LF: low frequency (0.03 - $0.15 \mathrm{~Hz})$; MF: mild frequency $(0.15-0.50 \mathrm{~Hz})$; $\mathrm{HF}$ : high frequency $(0.50-1.00 \mathrm{~Hz})$

Table 4. The logistic regression model, and determinants of the risk of fetal acidosis

\begin{tabular}{|c|c|c|c|c|c|}
\hline Variable & $\begin{array}{l}\text { Unit/difference }\left(90^{\text {th }}\right. \\
\left.-10^{\text {th }}\right) \text { or reference }\end{array}$ & $\begin{array}{c}\text { Slope } \\
\text { coefficient }\end{array}$ & $\begin{array}{c}\text { OR }[95 \% \mathrm{Cl}] \\
\text { per unit or according } \\
\text { to a reference } \\
\end{array}$ & $\begin{array}{c}\text { OR }[95 \% \mathrm{Cl}] \\
\text { per difference }\left(90^{\text {th }}-10^{\text {th }}\right)\end{array}$ & $\mathrm{p}$ \\
\hline Nulliparity & yes vs. no & 0.570 & $1.769[1.362-2.300]$ & - & $<0.0001$ \\
\hline Term & $1 \mathrm{WA}$ & 0.287 & $1.333[1.189-1.497]$ & - & $<0.0001$ \\
\hline Sex of the newborn & male vs. female & 0.342 & $1.408[1.097-1.811]$ & - & $<0.01$ \\
\hline $\begin{array}{l}\text { Time interval between the end } \\
\text { of recording and the delivery }\end{array}$ & $\begin{array}{c}1 \mathrm{~min} \\
\Delta 30 \min \\
\end{array}$ & 0.021 & $1.022[1.012-1.031]$ & $1.906[1.443-2.515]$ & $<0.0001$ \\
\hline Minimum expected value MEV & $\begin{array}{c}1 \mathrm{bpm} \\
\Delta 40 \mathrm{bpm}\end{array}$ & 0.019 & 1.019 [1.007 - 1.032] & $2.169[1.344-3.511]$ & $<0.01$ \\
\hline Mean baseline - mean FHR & $\begin{array}{c}1 \mathrm{bpm} \\
\Delta 4 \mathrm{bpm}\end{array}$ & 0.256 & $1.292[1.174-1.424]$ & $2.786[1.905-4.117]$ & $<0.0001$ \\
\hline $\begin{array}{l}\text { Time during which the baseline } \\
\text { was below } 110 \mathrm{bpm}\end{array}$ & $\begin{array}{c}1 \% \\
\Delta 10 \% \\
\end{array}$ & 0.037 & $1.038[1.003-1.075]$ & $1.445[1.026-2.057]$ & $<0.05$ \\
\hline Baseline range & $\begin{array}{c}1 \mathrm{bpm} \\
\Delta 30 \mathrm{bpm}\end{array}$ & 0.027 & $1.027[1.014-1.040]$ & $2.230[1.539-3.247]$ & $<0.0001$ \\
\hline Total area for late decelerations & 1 beat & 0.002 & $1.002[1.000-1.005]$ & & $<0.05$ \\
\hline
\end{tabular}




\begin{tabular}{|c|c|c|c|c|c|}
\hline & & & & & \\
\hline & $\Delta 100$ beats & & & $1.268[1.023-1.582]$ & \\
\hline ITI & $1 \mathrm{msec}$ & & $1.048[1.021-1.075]$ & & \\
\hline LII & $\Delta 15 \mathrm{msec}$ & 0.047 & & $2.017[1.369-2.974]$ & $<0.001$ \\
\hline CTVU & $1 \mathrm{bpm}$ & & $0.950[0.925-0.975]$ & & \\
\hline 列 & $\Delta 15 \mathrm{bpm}$ & -0.051 & & $0.463[0.313-0.681]$ & $<0.001$ \\
\hline
\end{tabular}

The variables are expressed according to a reference (if qualitative) or per unit and as the difference between the variable's 90th percentile and 10th percentile (if quantitative).

LTI: long term irregularity; STV II: interval index short term variability 
Table S1. FHR-related data (Supplementary material)

\begin{tabular}{|c|c|c|c|c|c|c|}
\hline & Variable & Description & Type & $\begin{array}{l}\text { Coding or } \\
\text { unit }\end{array}$ & $\begin{array}{l}\text { Behavior } \\
\text { expected in the } \\
\text { event of } \\
\text { acidosis }\end{array}$ & References \\
\hline \multirow{3}{*}{ Characteristics } & Total time in labour & Duration of labor, in minutes & $\mathrm{N}$ & $\min$ & & \\
\hline & $\begin{array}{l}\text { Time interval between the end of the FHR recording and } \\
\text { birth }\end{array}$ & Time interval between the end of the FHR recording and birth & $\mathrm{N}$ & $\min$ & & \\
\hline & Signal loss & Percentage time with loss of signal & $\mathrm{N}$ & $\%$ & & \\
\hline \multirow{6}{*}{$\begin{array}{l}\text { FHR and signal } \\
\text { stability }\end{array}$} & Signal stability index x 100 & $\begin{array}{l}\text { Signal stability index (x 100) } \\
\text { The lower the SSI, the less often the FHR is at baseline and the } \\
\text { more likely it is to be abnormal }\end{array}$ & $\mathrm{N}$ & $\mathrm{bpm}^{-1}$ & $\downarrow$ & 10 \\
\hline & Minimum expected value MEV & $\begin{array}{l}\text { Minimum expected value } \\
\text { The lower the MEV, the more the FHR falls to the nadir of the } \\
\text { decelerations and the more likely it is to be abnormal }\end{array}$ & $\mathrm{N}$ & bpm & $\downarrow$ & \\
\hline & Presence of an unassignable baseline in the null zone & $\begin{array}{l}\text { Presence of unassignable baseline in the null zone (defined as } \\
\mathrm{SSI}<0.022 \text { and } \mathrm{MEV}<70 \mathrm{bpm})\end{array}$ & $\mathrm{F}$ & yes / no & $\uparrow$ & \\
\hline & $\begin{array}{l}\text { Presence of an unassignable baseline in the intermediate } \\
\text { zone }\end{array}$ & $\begin{array}{l}\text { Presence of unassignable baseline in the intermediate zone } \\
\text { (defined as SSI }<0.048 \text { and } \mathrm{MEV}<86 \mathrm{bpm} \text { ) }\end{array}$ & F & yes / no & $\uparrow$ & \\
\hline & FHR range & $\begin{array}{l}\text { Maximum FHR - minimum FHR in the FHR recording, apart } \\
\text { from } \mathrm{A} / \mathrm{D}\end{array}$ & $\mathrm{N}$ & bpm & $\uparrow$ & 8,81 \\
\hline & Standard deviation of the FHR & Standard deviation of the FHR, including the A/D & $\mathrm{N}$ & bpm & $\uparrow$ & $30,82,83$ \\
\hline \multirow{6}{*}{ Baseline } & Mean baseline - mean FHR & $\begin{array}{l}\text { Mean baseline - mean FHR in the recording } \\
\text { Mean basenn }\end{array}$ & $\mathrm{N}$ & bpm & $\uparrow$ & \\
\hline & Time during which the baseline was below $110 \mathrm{bpm}$ & Percentage of time during which the baseline is below $110 \mathrm{bpm}$ & $\mathrm{N}$ & $\%$ & $\uparrow$ & \\
\hline & Time during which the baseline above $160 \mathrm{bpm}$ & Percentage of time during which the baseline is above $160 \mathrm{bpm}$ & $\mathrm{N}$ & $\%$ & $\uparrow$ & \\
\hline & Baseline area below $110 \mathrm{bpm}$ & $\begin{array}{l}\text { When the baseline is }<110 \mathrm{bpm} \text {, the number of missed beats } \\
\text { relative to a constant rate at } 110 \mathrm{bpm}\end{array}$ & $\mathrm{N}$ & beats & $\uparrow$ & \\
\hline & Baseline area above $160 \mathrm{bpm}$ & $\begin{array}{l}\text { When the baseline is > à } 160 \mathrm{bpm} \text {, the number of extra beats } \\
\text { relative to a constant rate at } 160 \mathrm{bpm}\end{array}$ & $\mathrm{N}$ & beats & $\uparrow$ & \\
\hline & Baseline range & $\begin{array}{l}\text { Baseline range (max baseline - min baseline) during the } \\
\text { recording }\end{array}$ & $\mathrm{N}$ & bpm & $\uparrow$ & \\
\hline \multirow{2}{*}{ Accelerations } & Total number of accelerations & Number of accelerations & $\mathrm{E}$ & & $\downarrow$ & \\
\hline & Total acceleration area & Total acceleration area & $\mathrm{N}$ & bpm & $\downarrow$ & \\
\hline \multirow{4}{*}{ Decelerations } & Total number of decelerations & Number of decelerations (all types) & $\mathrm{E}$ & & $\uparrow$ & 2 \\
\hline & Total deceleration area & Total deceleration area (all types) & $\mathrm{N}$ & beats & $\uparrow$ & \\
\hline & Area: prolonged decelerations (>180 s) & Total area for prolonged decelerations $(>180 \mathrm{~s})$ & $\mathrm{N}$ & beats & $\uparrow$ & \\
\hline & Area: prolonged decelerations (> $120 \mathrm{~s}$ ) & Total area for prolonged decelerations $(>120 \mathrm{~s})$ & $\mathrm{N}$ & beats & $\uparrow$ & \\
\hline
\end{tabular}




\begin{tabular}{|c|c|c|c|c|c|c|}
\hline & Number of early decelerations & $\begin{array}{l}\text { Number of early decelerations (caused by compression of the } \\
\text { fetus' head and that do not reflect hypoxia }{ }^{84} \text { ) }\end{array}$ & $\mathrm{E}$ & & $\uparrow$ & 2 \\
\hline & Area: early decelerations & Total area for early decelerations & $\mathrm{N}$ & beats & $\uparrow$ & \\
\hline & Numbers of late decelerations & $\begin{array}{l}\text { Number of late decelerations (indicating a chemoreceptor- } \\
\text { mediated response to fetal hypoxemia }{ }^{84,85} \text { ) }\end{array}$ & $\mathrm{E}$ & & $\uparrow$ & 2 \\
\hline & Area: late decelerations & $\begin{array}{l}\text { Total area for late decelerations }\left({ }^{8,81}, \text { likely to stimulate }\right. \\
\text { chemoreceptors and indicate hypoxemia) }\end{array}$ & $\mathrm{N}$ & beats & $\uparrow$ & \\
\hline & Number of variable decelerations & $\begin{array}{l}\text { Number of variable decelerations (a baroreceptor response } \\
\text { during compression of the umbilical cord }{ }^{86} \text {, which is rarely } \\
\text { associated with significant hypoxia/fetal acidosis) }\end{array}$ & $\mathrm{E}$ & & $\uparrow$ & 2 \\
\hline & Area: variable decelerations & Total area for variable decelerations & $\mathrm{N}$ & beats & $\uparrow$ & \\
\hline & Presence of repetitive decelerations & $\begin{array}{l}\text { The decelerations are said to be "repetitive" if the ratio } \\
\text { (Number of decelerations / number of contractions) is greater } \\
\text { than } 0.5\end{array}$ & $\mathrm{~F}$ & yes / no & $\uparrow$ & 2 \\
\hline \multirow{5}{*}{$\begin{array}{l}\text { Long-term } \\
\text { variability } \\
\text { (LTV) }\end{array}$} & LTV & Change in the LTV & $\mathrm{N}$ & bpm & $\downarrow$ & $24,25,81$ \\
\hline & Low LTV $<6$ bpm & Minimum LTV, abnormal < $6 \mathrm{bpm}$ & $\mathrm{N}$ & $\%$ & $\uparrow$ & $\begin{array}{l}\text { Abnormal LTV }{ }^{8} \\
\text { OSC.Sil }^{26}\end{array}$ \\
\hline & Marked LTV > 25 bpm & Marked LTV $>25$ bpm & $\mathrm{N}$ & $\%$ & $\uparrow$ & OSC.Salt ${ }^{26}$ \\
\hline & Area under the LTV curve $<6 \mathrm{bpm}$ & Area under the LTV curve $<6 \mathrm{bpm}$ & $\mathrm{N}$ & & $\uparrow$ & \\
\hline & LTI & De Haan's long-term irregularity index. & $\mathrm{N}$ & msec & $\downarrow$ & $24-26,80,81$ \\
\hline \multirow{5}{*}{$\begin{array}{l}\text { Short-term } \\
\text { variability } \\
\text { (STV) }\end{array}$} & SD STV & $\begin{array}{l}\text { Standard deviation of STV } \\
\text { Standard devian of }\end{array}$ & $\mathrm{N}$ & bpm & $\downarrow$ & $26,30,81,82,87,88$ \\
\hline & STV $<1 \mathrm{bpm}$ & STV below 1 bpm, abnormal according to ${ }^{8}$ & $\mathrm{~N}$ & $\%$ & $\uparrow$ & 8 \\
\hline & STV II x 100 & $\begin{array}{l}\text { The STV interval, representing the coefficient of variation for } \\
\text { the difference in STV between consecutive samples. } \\
\text { For scaling reasons, the result is multiplied by } 100 \text {. }\end{array}$ & $\mathrm{N}$ & bpm & $\downarrow$ & $30,88,89$ \\
\hline & STV & Conventional STV & $\mathrm{N}$ & bpm & & $26,30,81,82,87,88$ \\
\hline & STI x 100 & $\begin{array}{l}\text { De Haan's short-term irregularity index. } \\
\text { For scaling reasons, the result is multiplied by } 100 .\end{array}$ & $\mathrm{N}$ & radians & $\uparrow$ & $11,26,27,90$ \\
\hline \multirow{5}{*}{$\begin{array}{l}\text { Frequency- } \\
\text { related }\end{array}$} & $\mathrm{P}_{\mathrm{VLF}} \times 100$ & Power in the very low frequency band $(0.01-0.03 \mathrm{~Hz})(\mathrm{x} 100)$ & $\mathrm{N}$ & $\mathrm{bpm}^{2}$ & $\uparrow$ & $29,30,89-92$ \\
\hline & $\mathrm{P}_{\mathrm{LF}} \times 100$ & Power in the low frequency band $(0.03-0.15 \mathrm{~Hz})(\mathrm{x} 100)$ & $\mathrm{N}$ & $\mathrm{bpm}^{2}$ & $\uparrow$ & \\
\hline & $\mathrm{P}_{\mathrm{MF}} \times 100$ & Power in the middle frequency band $(0.15-0.50 \mathrm{~Hz})(\mathrm{x} 100)$ & $\mathrm{N}$ & $\mathrm{bpm}^{2}$ & $\downarrow$ & \\
\hline & $\mathrm{P}_{\mathrm{HF}} \mathrm{X} 100$ & Power in the high frequency band $(0.50-1.00 \mathrm{~Hz})(\mathrm{x} 100)$ & $\mathrm{N}$ & $\mathrm{bpm}^{2}$ & $\downarrow$ & \\
\hline & $\mathrm{P}_{\mathrm{LF}} /\left(\mathrm{P}_{\mathrm{MF}}+\mathrm{P}_{\mathrm{HF}}\right)$ ratio & $\mathrm{P}_{\mathrm{LF}} /\left(\mathrm{P}_{\mathrm{MF}}+\mathrm{P}_{\mathrm{HF}}\right)$ ratio & & & $\uparrow$ & \\
\hline Wavelets & High frequency variability index HFVI & High frequency variability index & $\mathrm{N}$ & & $\downarrow$ & 37,93-95 \\
\hline
\end{tabular}

